\title{
Cellular Stress Responses: Cell Survival and Cell Death
}

\author{
Simone Fulda, ${ }^{1}$ Adrienne M. Gorman, ${ }^{2}$ Osamu Hori, ${ }^{3}$ and Afshin Samali ${ }^{2}$ \\ ${ }^{1}$ Children's Hospital, Ulm University, Eythstraße. 24, 89075 Ulm, Germany \\ ${ }^{2}$ School of Natural Sciences, National University of Ireland, Galway, University Road, Galway, Ireland \\ ${ }^{3}$ Kanazawa University Graduate School of Medical Science, Department of Neuroanatomy, Kanazawa City, \\ Ishikawa, 920-8640 Japan, Japan
}

Correspondence should be addressed to Simone Fulda, simone.fulda@uniklinik-ulm.de

Received 4 August 2009; Accepted 20 November 2009

Academic Editor: Srinivasa M. Srinivasula

Copyright ( $) 2010$ Simone Fulda et al. This is an open access article distributed under the Creative Commons Attribution License, which permits unrestricted use, distribution, and reproduction in any medium, provided the original work is properly cited.

Cells can respond to stress in various ways ranging from the activation of survival pathways to the initiation of cell death that eventually eliminates damaged cells. Whether cells mount a protective or destructive stress response depends to a large extent on the nature and duration of the stress as well as the cell type. Also, there is often the interplay between these responses that ultimately determines the fate of the stressed cell. The mechanism by which a cell dies (i.e., apoptosis, necrosis, pyroptosis, or autophagic cell death) depends on various exogenous factors as well as the cell's ability to handle the stress to which it is exposed. The implications of cellular stress responses to human physiology and diseases are manifold and will be discussed in this review in the context of some major world health issues such as diabetes, Parkinson's disease, myocardial infarction, and cancer.

\section{Overview of Cellular Stress Responses}

Cells respond to stress in a variety of ways ranging from activation of pathways that promote survival to eliciting programmed cell death that eliminates damaged cells. The cell's initial response to a stressful stimulus is geared towards helping the cell to defend against and recover from the insult. However, if the noxious stimulus is unresolved, then cells activate death signaling pathways. The fact that the cell's survival critically depends on the ability to mount an appropriate response towards environmental or intracellular stress stimuli can explain why this reaction is highly conserved in evolution. For example, antioxidant defence mechanisms against oxidative injury and stress proteins such as heat shock proteins occur in lower organisms as well as the mammals.

There are many different types of stress and the response a cell mounts to deal with these conditions will depend on the type and level of the insult. For example, protective responses such as the heat shock response or the unfolded protein response mediate an increase in chaperone protein activity which enhances the protein folding capacity of the cell, thus counteracting the stress and promoting cell survival. The adaptive capacity of a cell ultimately determines its fate.
Therefore, depending on the level and mode of stress, different defense mechanisms and prosurvival strategies are mounted; however, if these are unsuccessful, then the cell death programs are activated to eliminate these damaged cells from the organism. The mechanism by which a cell dies, that is, apoptosis, necrosis, pyroptosis, or autophagic cell death, often depends on its ability to cope with the conditions to which it is exposed. In this review we initially discuss the different forms of cell death that can be activated by adaptive responses because activation of death signaling pathways is the ultimate response to all types of persistent irresolvable stress. In Section 3 we will discuss the many types of stress a cell can encounter and the different responses that are activated to survive adverse conditions. Finally, we will discuss the involvement or contribution of cellular stress responses to disease states.

\section{Stress-Induced Cell Death}

Cell death has many forms and shapes. Cell death research encompasses not only the study of programmed forms of cell death (both apoptosis and autophagic cell death), necrosis and other modes of cellular demise but also the role these 
phenomena play in physiological and pathological processes including development, aging, and disease.

The cell death field has attracted much attention in the last two decades, mainly because of its relevance to development, degenerative diseases, and cancer. However, the field of cell death research is by no means new [1]. The concepts of cellular demise and associated terminology have been evolving since the 19th century. The term programmed cell death refers to controlled or regulated forms of death associated with a series of biochemical and morphological changes [2-4]. The realization that some forms of cell death were biologically controlled or programmed has led to exploitation of these processes and has made profound impact in various fields of biology and medicine [5-7].

Nowadays, programmed cell death is synonymous with apoptosis; however, based on the original definition it also refers to autophagic cell death [8]. The term apoptosis was first used to describe a particular morphology of cell death [9] common to the vast majority of physiological cell deaths. This morphology includes shrinkage and blebbing of cells, rounding and fragmentation of nuclei with condensation, and margination of chromatin, shrinkage, and phagocytosis of cell fragments without accompanying inflammatory responses (in most cases) [9-11]. The morphology of cells undergoing apoptosis appeared dissimilar and distinct from the morphology associated with necrosis $[9,10]$. Necrosis, a term commonly used by pathologists, refers to any deaths associated with the loss of control of ionic balance, uptake of water, swelling, and cellular lysis $[12,13]$. This lysis releases many intracellular constituents, attracting immune cells and provoking an inflammatory response.

2.1. Apoptosis. During the 1980 s, apoptosis became the focus of attention, primarily because of the relative ease with which it could be distinguished morphologically from other types of cell death. Within a few years apoptosis and delineation of the underlying biochemical and molecular pathways dominated cell death research. The discoveries of the Bcl-2 family of proteins [14-16], death receptors [17], caspases [18], mitochondrial cytochrome $c$ release [19], and a role for the endoplasmic reticulum [20] in apoptosis were just a few major milestones in the history of the field. Today the morphological and biochemical changes associated with apoptosis are largely explained by activation of caspases, and apoptosis has become generally accepted as caspasedependent programmed cell death [21].

Of all the forms of cell death apoptosis is the best characterized and its highly regulated nature makes it an attractive target for therapeutic intervention. Apoptosis is highly conserved throughout evolution $[22,23]$ and plays a major physiological role in both embryonic development and aging $[22,24]$. Various types of cellular stress stimuli have been shown to trigger apoptosis, including chemotherapeutic agents, irradiation, oxidative stress, and ER stress. Caspases, a family of cysteine proteases, act as common death effector molecules in various forms of apoptosis [25]. Caspases are synthesized as inactive proenzymes, which upon activation cleave various substrates in the cytoplasm or nucleus. This leads to many of the morphologic features of apoptotic cell death, for example, polynucleosomal DNA fragmentation, loss of overall cell shape, and nuclear shrinking [22, 25-27].

During apoptosis caspases are activated by different mechanisms. Stimulation of death receptors of the tumor necrosis factor (TNF) receptor superfamily such as CD95 (APO-1/Fas) or TNF-related apoptosis inducing ligand (TRAIL) receptors by their respective ligands or agonistic antibodies results in receptor aggregation and recruitment of the adaptor molecule Fas-associated death domain (FADD) and procaspase-8 to form the death inducing signaling complex (DISC) [26]. Upon recruitment caspase-8 becomes activated and initiates apoptosis by direct cleavage of downstream effector caspases [26]. The mitochondrial pathway to caspase activation is initiated by the release from the mitochondrial intermembrane space of apoptogenic factors such as cytochrome $c$, apoptosis inducing factor (AIF), second mitochondria-derived activator of caspase $(\mathrm{Smac}) /$ direct IAP binding protein with low $\mathrm{pI}$ (DIABLO) or Omi/high-temperature requirement protein A2 (HtrA2) [28]. The release of cytochrome $c$ into the cytosol results in caspase- 3 activation through formation of the cytochrome c/Apaf-1/caspase-9-containing apoptosome complex [29]. Smac/DIABLO or Omi/HtrA2 promotes caspase activation through neutralizing the inhibitory effects of Inhibitor of Apoptosis Proteins (IAPs) [30]. Activation of caspases has to be tightly controlled because of the potential detrimental effects on cell survival if they are inappropriately activated. For example, resistance to apoptosis can be caused by aberrant function or expression of IAPs [30]. IAPs present a group of endogenous inhibitors of caspases with eight members in human cells, that is, XIAP, cIAP1, cIAP2, survivin, livin (ML-IAP), NAIP, Bruce (apollon), and ILP-2 [30]. All IAP proteins harbor one or more baculovirus IAP repeat (BIR) domains that mediate their inhibitory interaction with caspases [30]. Among the IAP family proteins, XIAP is the most potent inhibitor of caspases and blocks apoptosis by binding to active caspase- 3 and -7 and by interfering with caspase-9 activation [30].

In addition, the ratio of antiapoptotic versus proapoptotic Bcl-2 family proteins regulates apoptosis sensitivity. The Bcl-2 proteins comprise both anti-apoptotic family members, for example, Bcl-2, Bcl- $\mathrm{X}_{L}$, and $\mathrm{Mcl}-1$, and proapoptotic molecules such as Bax, Bak, and BH3 domain only molecules [31]. According to the direct activation model of $\mathrm{Bcl}-2$ protein activation, $\mathrm{BH} 3$-only proteins that function as direct activators (such as Bim and the cleaved form of Bid (tBid)), directly bind to Bax and Bak to stimulate their activation [32]. In this model, $\mathrm{BH} 3$-only proteins that act as sensitizers such as Bad promote apoptosis by binding to the prosurvival $\mathrm{Bcl}-2$ proteins [32]. In contrast, the indirect activation model proposes that $\mathrm{BH} 3$-only proteins activate Bax and Bak in an indirect manner by binding to the multiple anti-apoptotic $\mathrm{Bcl}-2$ proteins that inhibit Bax and Bak, which in turn leads to the release of Bax and Bak [33,34]. Moreover, apoptosis sensitivity may be controlled by IAPs, through the regulation of additional signaling cascades, for example, the NF- $\kappa \mathrm{B}$, JNK, TNFR, and the ubiquitin/proteasome pathway $[30,35]$. The anti-apoptotic mechanisms regulating cell 
death have also been implicated in conferring drug resistance to tumor cells.

2.2. Autophagic Cell Death. Autophagy (self-eating) is a multistep process that is characterized by the vesicular sequestration and degradation of long-lived cytoplasmic proteins and organelles, for example, mitochondria [36]. The resulting double-membrane vesicle is termed an autophagosome [36]. The discovery of autophagyrelated (atg) genes, first in yeast and subsequently in humans, has greatly enhanced the molecular understanding of the mechanisms that are involved in the control of autophagy [36]. The protein product of the tumor suppressor gene Beclin 1 is the mammalian homolog of Atg6 and forms a multiprotein complex together with Vps34, a class III phosphatidylinositol 3-kinase, UVRAG (UV irradiation resistance-associated tumor suppressor gene), and a myristylated kinase (Vps15, or p150 in humans) $[36,37]$. This complex is required for the initiation of the formation of the autophagosome. Once this complex forms, Vps34 becomes activated and catalyzes the generation of phosphatidylinositol-3-phosphate, which is required for vesicle nucleation.

Two major protein conjugation systems exist that are required for autophagosome formation, that is, the Atg12Atg5 conjugation and Atg8-phosphatidylethanolamine conjugation systems [38]. Mechanistically, both conjugation systems function in a manner that is closely related to ubiquitin conjugation to proteins, with corresponding conjugation-assisting enzymes that resemble the E1 and E2 enzymes in ubiquitin conjugation [38]. In the Atg12Atg 5 conjugation pathway, Atg12 is covalently conjugated to Atg5 with the help of the E1-like enzyme Atg7 and the E2-like enzyme Atg10 [36]. In the other conjugation pathway, phosphatidylethanolamine (PE) is conjugated to LC3, one of the mammalian homologues of Atg8 [36]. This process involves the sequential action of the protease Atg4, the E1-like enzyme Atg7 and the E2-like enzyme Atg3. Subsequently, lipid conjugation results in the conversion of the soluble form of LC3, that is, LC3-I, to the autophagicvesicle-associated form that is termed LC3-II [39]. Thus, LC3 is soluble under unstressed conditions and undergoes association with peripheral membranes of autophagosomes during the induction of autophagy. Via the fusion with lysosomes, the content of autophagosomes is degraded by the action of acid-dependent enzymes [36].

Autophagy is typically observed in cells that are exposed to a variety of metabolic and therapeutic stresses, including growth factor deprivation, inhibition of the receptor tyrosine kinase/Akt/ mammalian target of rapamycin (mTOR) signaling, shortage of nutrients, ischemia/reperfusion, inhibition of proteasomal degradation, the accumulation of intracellular calcium, and endoplasmic reticulum (ER) stress [4043]. Reactive oxygen species (ROS) may provide a common link between cellular stress signals and the initiation of autophagy, as ROS accumulation has been reported to result in inactivation of the cysteine protease ATG4, which in turn causes accumulation of the ATG8-phosphoethanolamine precursor that is required for the initiation of autophagosome formation [44]. The functional relationship between autophagy and cell death is complex in the sense that, under most cellular settings, autophagy functions as a stress adaptation that prevents cell death, whereas in some circumstances, it constitutes an alternative route to cell death. This complex interrelationship between autophagy and cell death implies that these responses are somewhat linked at the molecular level. However, the key molecular events that eventually determine whether autophagy is protective or destructive are still poorly understood.

Although it is still controversial whether autophagy is protective or toxic for the cells, accumulating evidence suggests that it has beneficial roles in the heart under both physiological and pathological conditions $[45,46]$. Autophagy was shown to mediate turnover of intracellular proteins and organelles in the heart and protect against hemodynamic stress [45]. Consistent with this, rapamycin, which induces autophagy by inhibiting mTOR, can protect myocardium against ischemia/reperfusion injury [47]. In contrast, recent studies also demonstrated that downregulation of the transcription factors, activating transcription factor 5 or 7 (ATF5 or ATF7), using siRNA prevented stress-induced cell death $[48,49]$, suggesting that the level or timing of autophagy may be critical for deciding the fate of the cells. Autophagic cell death has mainly been shown during development. However, during recent years accumulating evidences suggest that inhibition of apoptosis induces cell death that is either associated with or dependent on autophagy [48-50]. There is evidence of cross-talk between apoptosis and autophagy at the molecular level, particularly with regard to the Bcl-2 family. In addition to its role in inhibiting apoptosis, Bcl-2 has also been shown to inhibit autophagy [51,52] and autophagic cell death [53]. This effect is mediated through the ability of $\mathrm{Bcl}-2$ to interact with Beclin 1, a key protein in autophagosome formation [52]. In fact, Beclin 1 has been shown to be a novel BH3-only protein and to interact with a number of anti-apoptotic Bcl2 family members including $\mathrm{Bcl}-2, \mathrm{Bcl}-\mathrm{xL}, \mathrm{Bcl}-\mathrm{w}$, and $\mathrm{Mcl}-1$ [54-57].

2.3. Necrosis. Necrosis has been considered as an accidental mode of cell death for many years, implying that within a multicellular organism it is an unregulated process. However, there is now mounting evidence that the execution of necrotic cell death is also regulated by a set of signaling pathways [58-60]. For instance, death domain receptors, for example, TNFR1, and Toll-like receptors have been reported to trigger necrosis, in particular in the presence of caspase inhibitors [58]. In addition, necrotic cell death has been reported in response to cellular stress stimuli, including ischemia or glutamate excitotoxicity in neurons or cancer cells exposed to alkylating DNA damaging agents [6163]. Morphologically, necrosis is characterized by a gain in cell volume, swelling of organelles and plasma membrane rupture, which results in the loss of intracellular contents. Several signal transduction cascades have been described that are involved in the propagation of necrotic cell death. There 
is mounting evidence that the serine/threonine kinase RIP1 is one of the key mediators of necrotic cell death, at least in the case of death receptors or Toll-like receptors [64, 65]. Studies in RIP1-deficient leukemia cells revealed that RIP1 is required for death receptor-induced necrosis [66, 67]. Furthermore, RIP1 has been described to be required for lipopolysaccharide-induced cell death of macrophages [68]. In line with a central role of RIP1 in necrotic cell death, small molecule inhibitors of RIP1 kinase were reported to protect against ischaemic brain injury in an in vivo model of necrosis [69-71]. In addition to RIP1, there is very recent evidence that RIP3 is also critical for necrotic cell death [72-74]. To this end, RIP3 was identified in an RNA interference screen to be essential for necrosis in response to $\mathrm{TNF} \alpha$ stimulation and during virus infection $[72,73]$. RIP3 interacts with RIP1 and regulates RIP1 phosphorylation and the generation of ROS [72-74].

Moreover, ROS and calcium constitute important mediators that are involved in the propagation of the necrotic signal in various forms of necrosis, for example, upon stimulation with TNF $\alpha$ or exposure to double-stranded DNA $[75,76]$. ROS may be generated intracellularly by mitochondria and glycolysis [75, 77]. While the ER is the main intracellular calcium store, mitochondrial calcium has been described to stimulate oxidative phosphorylation, thereby promoting ROS generation [78]. Both ROS and calcium can cause damage to organelles and macromolecules, which contributes to the loss of cell integrity. In addition calcium-mediated activation of calpain can lead to cleavage and inactivation of caspases [79], whereas the ROS can target the active site of caspases and render them inactive [80]. Many stimuli that drive necrosis can inhibit the apoptotic machinery.

\section{Cellular Stress Responses}

During tissue homeostasis there is an equilibrium between the net growth rate and the net rate of cell death [22]. Upon exposure to cellular stress this physiological homeostasis is in danger. Depending on the type of cellular stress and its severity, the cell's response can be manifold. In essence, if the stress stimulus does not go beyond a certain threshold, the cell can cope with it by mounting an appropriate protective cellular response, which ensures the cell's survival. Conversely, the failure to activate or maintain a protective response, for example, if the stressful agent is too strong, results in activation of stress signaling cascades that eventually fuel into cell death pathways $[81,82]$.

3.1. The Heat Shock Response. One of the main prosurvival activities of cells, the heat shock response, was originally described as the biochemical response of cells to mild heat stress (i.e., elevations in temperature of $3-5^{\circ} \mathrm{C}$ above normal) $[83,84]$. It has since been recognized that many stimuli can activate this response, including oxidative stress and heavy metals. One of the main cellular consequences of these stresses is protein damage leading to the aggregation of unfolded proteins. In order to counteract this, cells increase the expression of chaperone proteins that help in the refolding of misfolded proteins and alleviate protein aggregation. This confers a transient protection, leading to a state that is known as thermotolerance, whereby cells become more resistant to various toxic insults, including otherwise lethal temperature elevations, oxidative stress, various anticancer drugs, and trophic factor withdrawal [8588].

During initiation of the heat shock response general protein transcription and translation is halted, presumably to alleviate the burden of misfolded proteins in the cell. However, transcription factors that enhance expression of a specific subset of protective genes are selectively activated under these conditions; these are the heat shock factors (HSFs) [89]. Vertebrate cells have three different HSFs: HSF1 is essential for the heat shock response and is also required for developmental processes, HSF2 and HSF4 are important for differentiation and development, while HSF3 is only found in avian cells and is probably redundant with HSF1 [90, 91]. Cells derived from mice lacking HSF1 are sensitive to stress and are unable to develop thermotolerance or induce heat responsive genes upon heat shock [92-94], which has confirmed that HSF1 in particular is responsible for the heat shock response. More recent work has shown that HSF2 can modulate HSF1-mediated expression of heatresponsive genes [95], suggesting that HSF2 also participates in transcriptional regulation of the heat shock response.

Inactive HSF1 is maintained in a monomeric form in the cytoplasm through interaction with Hsp90 and cochaperones [96, 97] (Figure 1). When the cell is exposed to stressful conditions, there is accumulation of unfolded proteins which compete with HSF1 for Hsp90 binding. Thus, HSF1 is released from the complex stimulating its transition from a monomer to a homotrimer that can translocate to the nucleus and bind to DNA (Figure 1). HSFs bind to upstream sequences (heat shock elements) in the promoters of target genes, leading to the expression of heat shock proteins (Hsps).

Hsps are a set of evolutionary conserved proteins that are grouped into subfamilies with molecular weights of approximately $110,90,70,60,40$, and $15-30 \mathrm{kDa}[85$, 98]. Some of these, for example, Hsp90, are constitutively expressed and act intracellularly as molecular chaperones, preventing premature folding of nascent polypeptides [99]. Others, particularly Hsp27 and Hsp70, are usually expressed at low basal levels and increase in response to environmental and physiological stressors, and as such they are termed inducible Hsps and are part of the heat shock response [85]. Hsp27 belongs to a subfamily of stress proteins, the small Hsps, which are detectable in virtually all organisms. Hsp27 is also regulated by phosphorylation and dynamic association/dissociation into multimers ranging from dimers to large oligomers [100]. Hsp70 is the inducible member of the $70 \mathrm{kDa}$ family of Hsps. Both Hsp27 and Hsp70 have been shown to protect cells against the induction of cell death by a variety of stresses and by different modes of cell death, including apoptosis $[86,101]$ and necrosis $[102-$ 104]. They achieve these effects directly, through inhibition of cell death pathways, and indirectly, through general prosurvival activities. For example, in their capacity as 


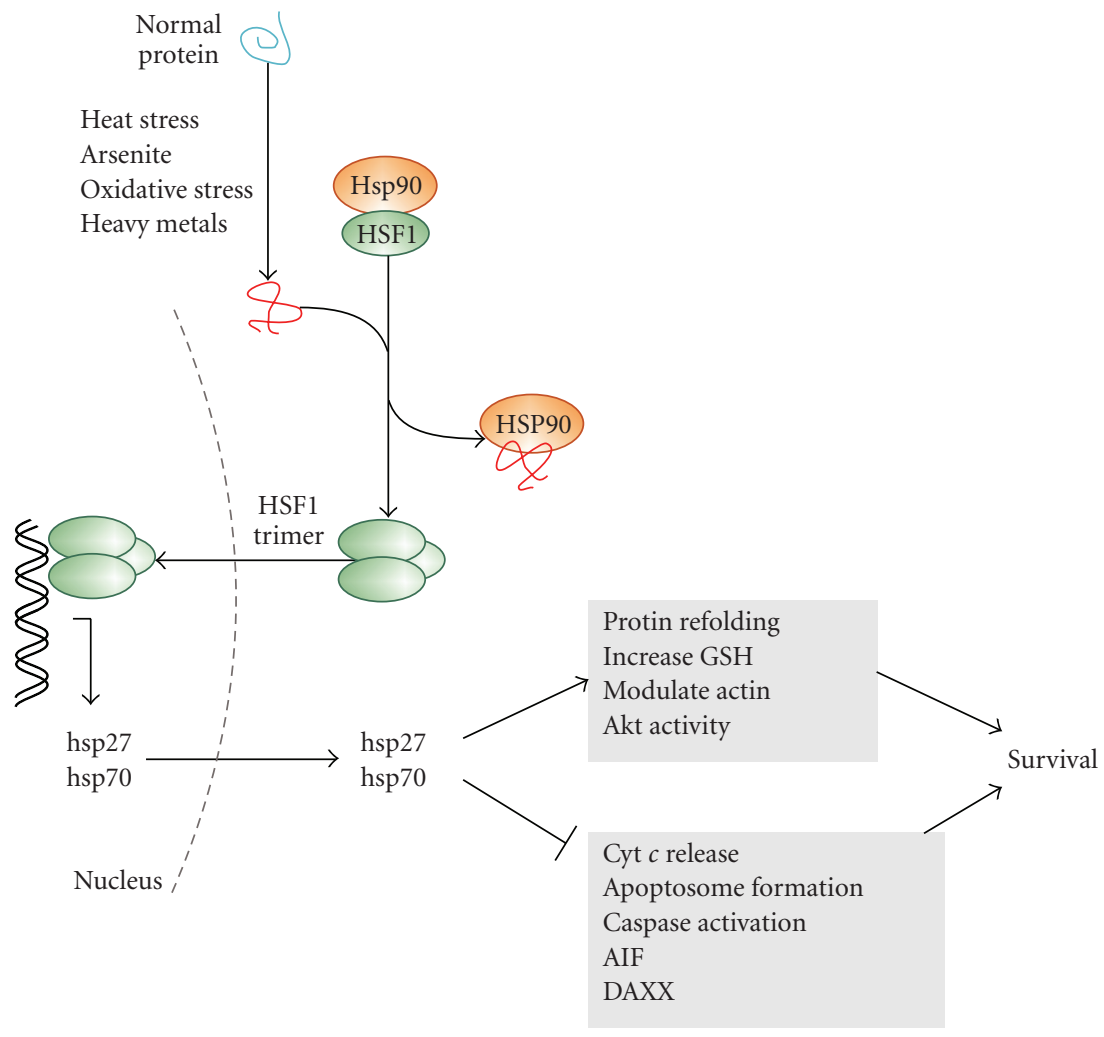

FIGURE 1: Induction of heat shock proteins inhibits apoptosis and promotes cell survival. Exposure of cells to elevated temperatures, oxidative stress, and heavy metals causes accumulation of unfolded proteins, which through activation of HSF1 leads to induction of Hsp27 and Hsp70. These Hsps inhibit apoptosis and promote survival.

molecular chaperones, inducible Hsps bind to and aid the refolding of unfolded proteins, thereby preventing protein aggregation [105]. Hsp27 can interact with actin and is thus important for maintaining the integrity of the cytoskeleton which may play a role in promoting survival [106].

Apart from these indirect mechanisms, Hsp27 and Hsp70 can directly inhibit apoptosis by modulating both the intrinsic and the extrinsic apoptosis pathways and by interfering with caspase activation at several different levels [107-109]. Both Hsp27 and Hsp70 have been reported to directly block release of pro-apoptotic factors, including cytochrome $c$, from the mitochondria [110-112]. In the cytosol, these Hsps can block apoptosome formation and activation of downstream caspases through their ability to bind to cytochrome $c$ and procaspase-3 (in the case of Hsp27) [107, 108] and procaspases -3, -7 and Apaf1 (in the case of Hsp70) [101, 113-115]. Hsp70 can also interact with and inhibit apoptosis-inducing factor (AIF) thus inhibiting apoptotic nuclear changes [116, 117]. Hsps can also modulate the death receptor pathway. Hsp27 is reported to inhibit DAXX, an adaptor protein that links the Fas death receptor and the ER stress sensor IRE1 to ASK-1 and downstream JNK pro-apoptotic signaling [118]. Hsp70 also inhibits JNK activity [119-121], although this is not observed in all systems [101]. Hsp27 and 70 can also interact with other proteins that regulate cell survival. For example, Hsp27 can interact with the prosurvival Ser/Thr kinase Akt which is suggested to be important for sustained Akt activity [122-124]. Hsp70 can exist in complex with cochaperones, including DnaJ/Hsp40 and BAG-1 which affect its ability to modulate apoptosis $[125,126]$. Overall, Hsps can be activated or induced by a number of stresses and they act to protect the cell by influencing a variety of cellular processes which determine cellular fate. Hsps are, in general, prosurvival and anti-apoptotic molecules.

3.2. The Unfolded Protein Response (UPR). Secretory and membrane proteins undergo posttranslational processing, including glycosylation, disulfide bond formation, correct folding, and oligomerization, in the ER. In order to effectively produce and secrete mature proteins, cellular mechanisms for monitoring the ER environment are essential. Exposure of cells to conditions such as glucose starvation, inhibition of protein glycosylation, disturbance of $\mathrm{Ca}^{2+}$ homeostasis and oxygen deprivation causes accumulation of unfolded proteins in the ER (ER stress) and results in the activation of a well orchestrated set of pathways during a phenomenon known as the unfolded protein response (UPR) [127, 128] (Figure 2). The UPR is generally transmitted through activation of ER resident proteins, most notably inositol-requiring protein-1 (IRE1), protein kinase RNA (PKR)-like ER kinase (PERK), and activating transcription factor 6 (ATF6). In some cells/tissues, additional ATF6-like 


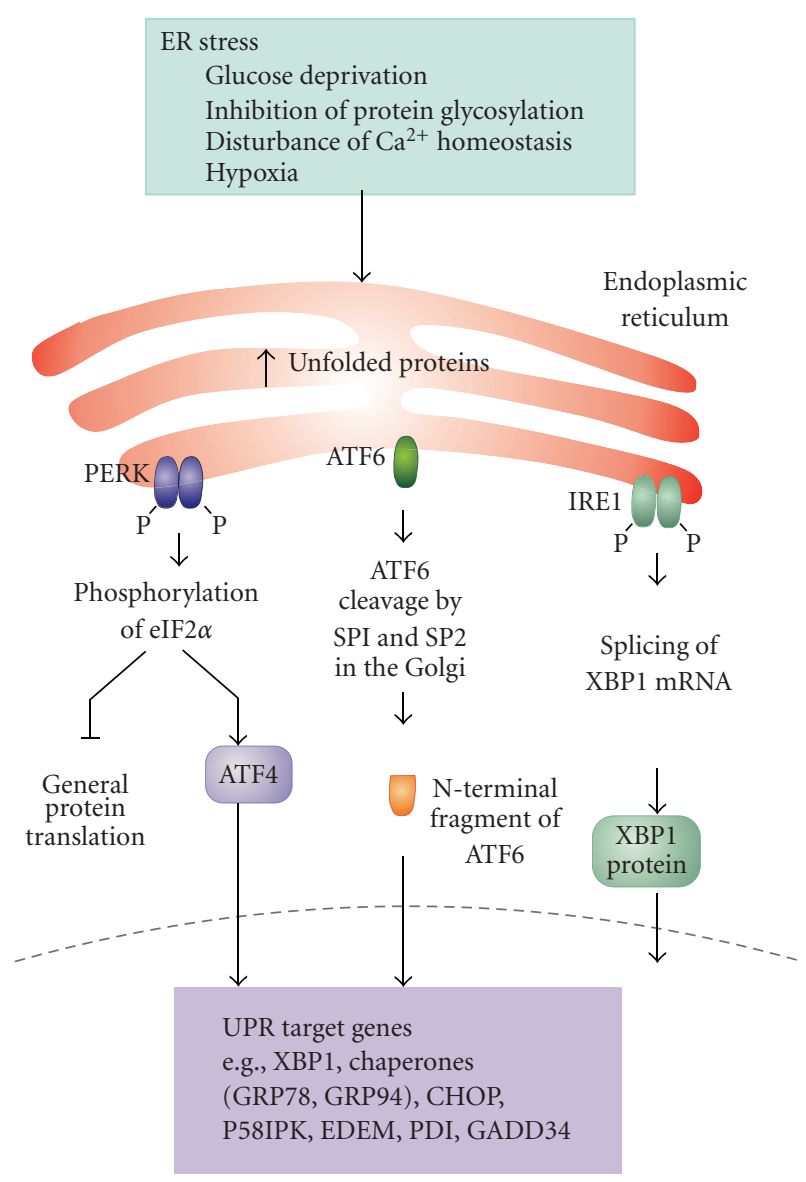

FIGURE 2: ER stress and the unfolded protein response. Stress to the ER stimulates the activation of the three endoplasmic reticulum (ER) stress receptors, PKR-like ER kinase (PERK), activating transcription factor 6 (ATF6) and inositol-requiring enzyme 1 (Ire1) that are involved in the unfolded protein response (UPR). PERK phosphorylates eukaryotic initiation factor 2 (eIF2 $\alpha$ ) which inhibits general protein translation, allowing eIF $2 \alpha$-independent translation of ATF4, which activates transcription of chaperones such as GRP78. ATF6 undergoes specific proteolysis in the Golgi apparatus which leads to activation. One of the ATF6 target genes is XBP1. IRE1 catalyzes the alternative splicing of XBP1 mRNA leading to expression of the active XBP1 transcription factor. Together the three arms of the UPR block protein translation, increase chaperone expression and enhance ER-associated protein degradative pathways.

bZip type transcription factors such as OASIS, CREB-H, Tisp40, and Luman also transmit the UPR signaling [129132]. The UPR target genes include molecular chaperones in the ER, folding catalysts, subunits of translocation machinery (Sec61 complex), ER-associated degradation (ERAD) molecules and anti-oxidant genes [127].

Among the UPR transmitters so far identified, IRE1 and PERK are both type I transmembrane protein kinases which dimerize to promote autophosphorylation and activation in response to ER stress. Activated IRE1 endonucleolytically cleaves mRNA that encodes a transcription factor named homologous to ATF/CREB1 (Hacl) in yeast $[133,134]$ and X-box binding protein-1 (XBP1) in higher species $[135,136]$. The spliced forms of Hacl and/or XBP1 in turn activate the transcription of the UPR target genes. In contrast, activated PERK phosphorylates the $\alpha$-subunit of eukaryotic translation initiation factor-2 (eIF2 $\alpha$ ) which leads to lower levels of eIF2 and translational suppression [137]. The PERK-eIF $2 \alpha$ signaling pathway also activates the transcription of the UPR target genes through CAP-independent upregulation of the translation of a transcription factor ATF4 [138]. PERK can also directly phosphorylate and activate the transcription factor, NF-E2-related factor-2 (Nrf2), which contributes to cellular redox homeostatis by inducing the expression of anti-oxidant genes [139, 140]. ATF6 is a type II transmembrane protein which is cleaved by Golgi apparatusresident proteases site- 1 protease $(\mathrm{SP} 1)$ and site- 2 protease (SP-2) in response to ER stress $[141,142]$. The cleaved Nterminal fragment of ATF6 acts as a transcription factor to increase the transcription of the UPR target genes together with XBP1 and ATF4.

UPR signaling generally promotes cell survival by improving the balance between the protein load and the folding capacity in the ER and/or by improving the secretion of trophic factors/growth factors [143, 144]. However, if the protein load in the ER exceeds its folding capacity, or some defects in the UPR exist, cells tend to die, typically, with apoptotic features (ER stress-induced cell death). Although the exact molecular mechanisms that regulate this type of cell death remain to be elucidated, at least three pathways have been identified as being involved: the caspase12/caspase-4 pathway and CHOP and IRE1-JNK pathways. Caspase-12 [145] in mice and caspase-4 in human [146] have been proposed as caspases that initiate ER stressinduced cell death. Caspase-12 null mice are reported to be relatively resistant to ER stress and amyloid-beta toxicity [145]. Caspase-12 is reported to directly cleave procaspase9 without involvement of the cytochrome $c /$ Apaf-1 pathway [147]. C/EBP homologous protein (CHOP), a transcription factor that is induced downstream of PERK and ATF6 pathways, induces ER stress-induced cell death at least in part by suppressing the expression of $\mathrm{Bcl}-2$ [148] and inducing Bim expression [149]. IRE1 also participates in ER stressinduced cell death by activating JNK through the binding with ASK1 and Traf2 [150, 151].

Important roles for ER stress and ER stress-induced cell death have also been demonstrated in a broad spectrum of pathophysiological situations, including ischemia, diabetes, atherosclerosis, endocrine defects, development, neurodegenerative disorders, and cancer as described below [143, 144, 152-155].

Among the UPR targets, glucose-regulated proteins (GRPs) are the most studied and best characterized. GRPs were originally identified as proteins induced by glucose starvation [156]. Later, it was found that these molecules were transcriptionally induced by ER stress through the cisacting element termed ER stress response element (ERSE) [157]. GRPs include molecular chaperones in the ER such as GRP78/Bip, GRP94, ORP150/GRP170, and oxidoreductases in the ER such as PDI, ERp72, and GRP58/ERp57. Accumulating evidence suggests that GRPs promote cell survival 
when exposed to stresses such as hypoxia/ischemia [143, 158], glutamate excitotoxicity [159], and neurodegeneration [160-162]. GRP78 could be a potential factor to inhibit atherosclerosis by preventing ER stress-induced cell death in endothelial cells [163]. This involves the inhibition of the activation of SREBPs, a molecule that induces cholesterol and triglyceride biosynthesis, or by inhibiting tissue factor procoagulant activity [164-166]. ORP150/GRP170 was found to be associated with insulin sensitivity in both human and mice as described below. Furthermore, GRPs also play important roles in survival during early mammalian development [159, 167-169].

Interestingly, recent studies have revealed that small compounds that mimic the functions of GRPs (chemical chaperones) and those that induce endogenous GRPs (molecular chaperone inducers) can prevent protein aggregation [170], improve protein secretion [171], and protect cells against brain ischemia [172] or neurodegeneration [173]. These results suggest that the regulation of ER stress can be a novel therapeutic target in a variety of diseases.

3.3. The DNA Damage Response. Upon cellular stress conditions that are caused by exposure to chemotherapeutic agents, irradiation, or environmental genotoxic agents such as polycyclic hydrocarbons or ultraviolet (UV) light, damage to DNA is a common initial event $[174,175]$. DNA double strand breaks (DSBs) and single strand breaks (SSBs) are considered as key lesions that initiate the activation of the DNA damage response [174]. Since the DNA duplex is more vulnerable to chemical attack or nucleases when it is separated into two single-stranded DNA strands, for example, during DNA replication and transcription, SSBs are preferentially generated under these conditions [176]. Defined SSBs are also generated during distinct pathways of DNA repair, for example, in the course of nucleotide excision repair (NER). After DNA damage recognition, dual incision $5^{\prime}$ to the DNA lesion by ERCC1-XPF and $3^{\prime}$ to the damage by XPG results in the removal of the lesion-containing oligonucleotide [177]. DSBs are produced directly or indirectly by many anticancer drugs, including DNA intercalating, alkylating or crosslinking agents, topoisomerase inhibitors, and nucleotide analogs [174]. Once DSBs are generated, ataxia telangiectasia mutated (ATM) is recruited by the MRE-11-Rad50-NBS1 (MRN) complex to sites of broken DNA and phosphorylates downstream substrates such as checkpoint kinase 2 (Chk2) and p53 $[175,178]$ (Figure 3). p53 induces transcriptional activation of different functional programs, for example, cell cycle regulatory proteins such as p21 and pro-apoptotic factors such as CD95, PUMA, and BAX [179]. In addition, recent studies have also defined a nontranscriptional pro-apoptotic activity of p53 that regulates the intrinsic mitochondriamediated pathway of apoptosis [180]. Damage to DNA engages DNA repair processes to ensure the cell's survival in the case of sublethal damage [174]. Alternatively, if the damage is too severe to be repaired-the DNA-damaging insult is transmitted by the cellular stress response to the activation of effector systems to mediate cell death [174]. In the latter case, various stress-inducible molecules, including NF- $\kappa \mathrm{B}, \mathrm{p} 53$, JNK, or MAPK/ERK, have been implicated in propagating and modulating the cell death signal $[81,82]$.

Depending on the type of lesion, DNA damage initiates one of several mammalian DNA repair pathways, which eventually restore the continuity of the DNA double strand. There are two main pathways for the repair of DSBs, that is, nonhomologous end-joining and homologous recombination $[181,182]$. The former constitutes the predominant DNA repair pathway in humans and involves DNA repair proteins such as DNA-PK, Ku70, and Ku80 [181, 182]. Base damage can be repaired either by enzyme-catalyzed reversal or alternatively via excision repair [183]. Mismatch repair is responsible for the removal of incorrectly paired nucleotides [184]. It is important to note that DNA repair can, in principle, be error-free and error-prone. Several proteins have been discovered recently that exert a specific function in error-free repair processes to guarantee high-fidelity reconstitution of the DNA [185]. Faithful genome transmission requires the coordination of this highly complex network of DNA repair pathways and repair surveillance mechanisms linked to cell cycle checkpoints as well as cell death mechanisms [185]. Error-prone repair or complete failure of DNA repair cannot only lead to mutations but can also lead to the initiation of cell death pathways [185].

3.4. The Response to Oxidative Stress. Cell survival requires appropriate proportions of molecular oxygen and various antioxidants. Reactive products of oxygen are amongst the most potent and omnipresent threats faced by cells. These include ROS such as superoxide anion $\left(\mathrm{O}_{2}{ }^{--}\right)$, hydrogen peroxide $\left(\mathrm{H}_{2} \mathrm{O}_{2}\right)$, singlet oxygen, hydroxyl radical $\left(\mathrm{OH}^{\bullet}\right)$, peroxy radical, as well as the second messenger nitric oxide $\left(\mathrm{NO}^{\bullet}\right)$ which can react with $\mathrm{O}_{2}{ }^{\bullet-}$ to form peroxynitrite $\left(\mathrm{ONOO}^{-}\right)$. Normally in cells there exists equilibrium between pro-oxidant species and antioxidant defense mechanisms such as ROS-metabolizing enzymes including catalase, glutathione peroxidase, and superoxide dismutases (SODs) and other antioxidant proteins such as glutathione (GSH) (Figure 4). Oxidative stress occurs when there is a disturbance in this pro-oxidant:antioxidant balance and it has been implicated in several biological and pathological processes [186]. Although most oxidative insults can be overcome by the cell's natural defenses, sustained perturbation of this balance may result in either apoptotic or necrotic cell death [186-190].

ROS can emanate from intracellular or extracellular sources. Auto-oxidation of reduced respiratory components of the mitochondrial electron transport chain causes the production of free radical intermediates, $\mathrm{O}_{2}^{--}$and $\mathrm{H}_{2} \mathrm{O}_{2}$, which in the presence of iron can produce highly reactive $\mathrm{OH}^{\bullet}$ radical via the Fenton reaction. These ROSs are dealt with by SODs, enzymes considered to be the first line of defense against oxygen toxicity. ROS can also be produced in the cytosol. For example, the arachidonic acid cascade, yielding prostaglandins, and leukotrienes may generate ROS when the released lipid is metabolized [191], and some cytochrome P-450 isozymes are well-known ROS producers 


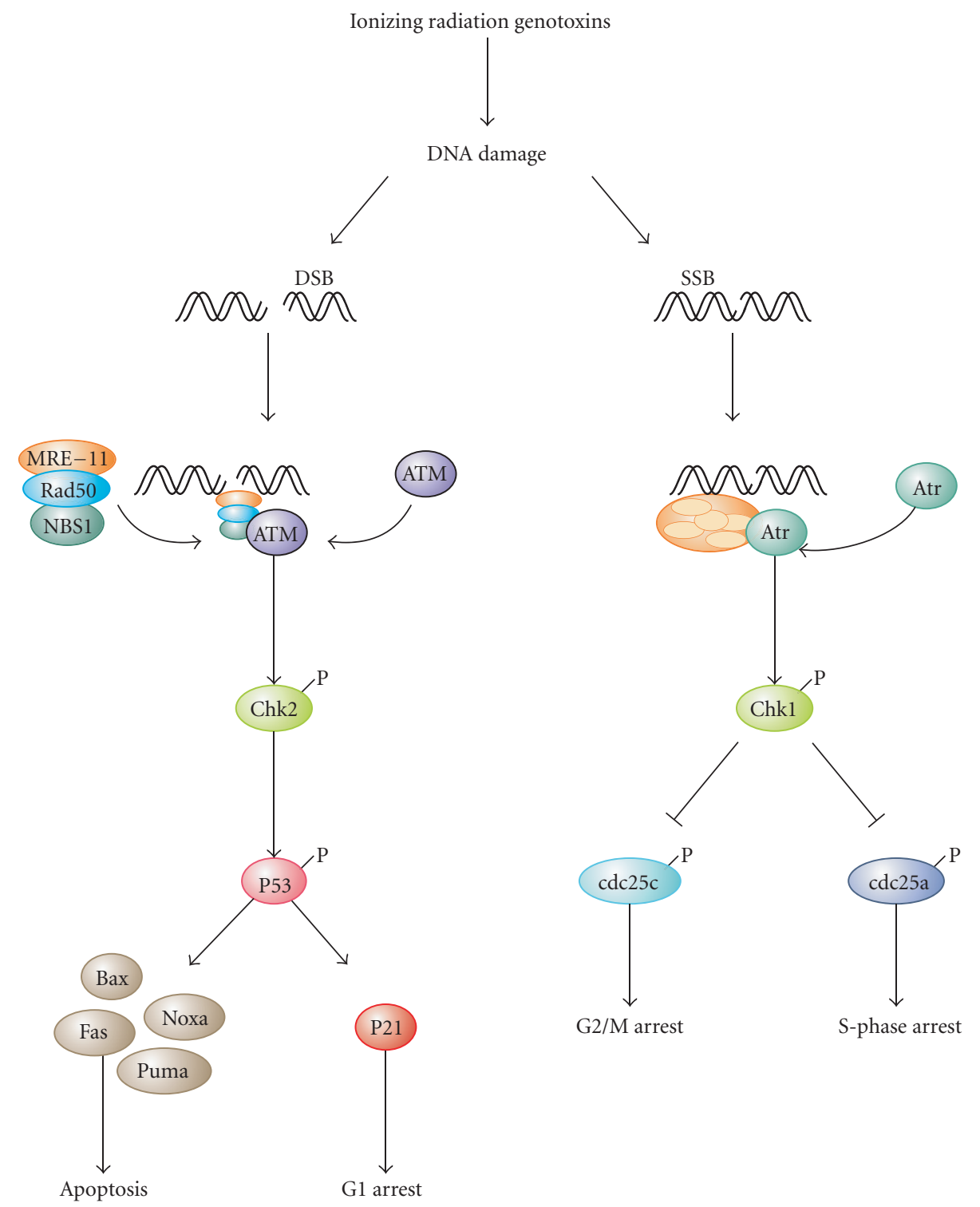

FIGURE 3: DNA damage responses and cell death. Upon exposure to ionizing radiation or genotoxins, the damage to DNA is a common initial event. DNA double strand breaks (DSBs) or single strand breaks (SSBs) are considered to be key lesions that initiate activation of the DNA damage response. Upon DSBs, ataxia telangiectasia mutated (ATM) is recruited by the MRE-11-Rad50-NBS1 (MRN) complex to sites of broken DNA and phosphorylates downstream substrates such as checkpoint kinase 2 (Chk2), which subsequently phosphorylates p53. Sublethal damage to DNA can engage survival pathways via p21-mediated cell cycle arrest. Alternatively-if the damage is too severe to be repaired-pro-apoptotic p53 target genes are activated including Bax, Puma, Noxa, and Fas, which promote apoptosis. Upon SSBs, it is ataxia telangiectasia and Rad3 related (ATR) that gets activated and phosphorylates Chk1. Chk1 in turn phosphorylates and inhibits cdc25c to mediated G2/M arrest or alternatively cdc25a to promote S-phase arrest.

[192]. Also, the auto-oxidation reactions of ascorbic acid, low molecular weight thiols, adrenalin, and flavin coenzymes can cause ROS production. In many of these cases, cytosolic GSH neutralizes the offenders. In addition to physiological sources of ROS, diverse exogenous agents can contribute to the intracellular production of free radicals. Most of these compounds cause the generation of $\mathrm{O}_{2}{ }^{\cdot-}$ and $\mathrm{H}_{2} \mathrm{O}_{2}$ $[80,193,194]$. The mechanism of action of many exogenous agents involves redox cycling whereby an electron is accepted to form a free radical and it is then transferred to oxygen.
Interestingly, there is evidence of cross-talk between oxidative stress and other stress response pathways. For example, oxidative stress is known to cause an increase in the expression of certain inducible Hsps, particularly Hsp27 [195-197]. Hsps have been reported to protect against many stresses apart from heat shock, including heavy metals, radiation, nitric oxide, and other oxidants. In addition, activation of the UPR stimulates upregulation of antioxidant genes through PERK-dependent phosphorylation of the Nrf2 transcription factor, whose target genes include 


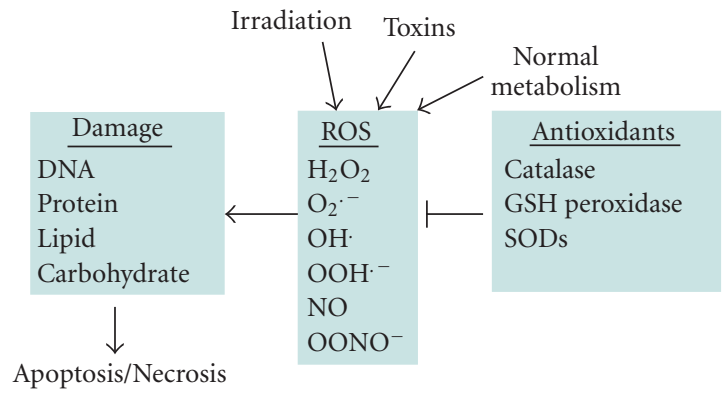

Figure 4: Oxidative stress and cell death. There is a plethora of stimuli that can trigger the generation of reactive oxygen species (ROS), among them irradiation, toxins, and also normal metabolic processes. A range of different ROS species have been identified, which are kept in check by antioxidant defenses. These include several detoxifying enzymes, for example, catalase, GSH peroxidase, and superoxide dismutase (SOD). If these antioxidants defense mechanisms are too weak, ROS-mediated damage to cellular macromolecules will eventually lead to cell death.

enzymes involved in GSH biosynthesis, and heme oxygenase1 [198]. Moreover, perturbations in cellular redox status sensitize cells to the harmful effects of ER stress [199]. Similarly, accumulating evidence suggests a role for $\mathrm{O}_{2}{ }^{--}$in the activation of autophagy [200].

ROS can cause damage to all of the major classes of biological macromolecules, including nucleic acids, proteins, carbohydrates, and lipids. When the cell's antioxidant defenses are overwhelmed, ROS can induce cell death. Numerous, recent studies have shown that the mode of cell death that occurs depends on the severity of the insult [187189]. In fact, oxidants and antioxidants not only determine cell fate, but can also modulate the mode of cell death $[186,190]$.

Many cytotoxic agents induce ROS, including peroxide and $\mathrm{O}_{2}{ }^{--}$, which are involved in the induction of apoptotic cell death [201]. $\mathrm{H}_{2} \mathrm{O}_{2}$ can cause the release of cytochrome $c$ from mitochondria into the cytosol and $\mathrm{H}_{2} \mathrm{O}_{2}$ may also activate nuclear transcription factors, like NF- $\kappa \mathrm{B}, \mathrm{AP}-1$, and p53 [202], which may upregulate death proteins or produce inhibitors of survival proteins. One model proposed for $\mathrm{H}_{2} \mathrm{O}_{2}$ induction of apoptosis is upregulation of the Fas-FasL system, leading to activation of caspase- 8 and downstream caspases $[203,204]$. It is also possible that $\mathrm{NO}^{\bullet}$ may also inactivate several antioxidant enzymes, including catalase, glutathione peroxidase, and superoxide dismutases [205, 206]. Also, $\mathrm{NO}^{\bullet}$ has been reported to induce apoptosis by increasing ceramide generation through caspase-3 activation, induction of mitochondrial permeability transition, and activation of the Fas system [207].

Certain anti-apoptotic proteins have also been reported to have antioxidant roles. An early suggestion regarding the mechanism of action of $\mathrm{Bcl}-2$ was that it inhibited cell death by reducing the generation of reactive oxidants, thus preventing critical intracellular oxidations that are requisite for the completion of the apoptotic program [208]. However, it is now understood that the reduction in ROS observed with $\mathrm{Bcl}-2$ overexpression is probably the result of its ability to prevent loss of cytochrome $c$ from mitochondria. Yet it is interesting to note that separate studies illustrate that Bcl-2overexpressing cells have higher levels of total cellular GSH [209]. The product of the baculovirus p35 gene, a potent anti-apoptotic protein, is thought to have antioxidant role and is protective against many apoptotic stimuli including growth factor withdrawal, staurosporine, glucocorticoid, and actinomycin-D treatment, and is a broad-spectrum caspase inhibitor [210]. However, caspase inhibition may not be p35's sole mechanism of cytoprotection. Expression of the p35 gene inhibits $\mathrm{H}_{2} \mathrm{O}_{2}$-induced apoptosis in insect cells and may be acting as a sink for free radicals [211].

However, ROS are also reported to interfere with the apoptosis death program, compelling cells to adopt an alternative mode of cell death. Apoptotic cell death can be switched to necrosis during oxidative stress by two possible mechanisms: inactivation of caspases or a drop in cellular levels of ATP levels. Caspases contain an active site cysteine nucleophile [212] which is prone to oxidation or thiol alkylation as well as S-nitrosylation [80, 213, 214]. This leads to their inactivation, switching the mode of cell death to necrosis $[80,214]$. $\mathrm{NO}^{\bullet}$ may act as a molecular switch to control protein function via reactive thiol groups. For example, $\mathrm{NO}^{\bullet}$-mediated inhibition of apoptosis in most cases is due to direct inhibition of caspase activity through S-nitrosylation of the active site cysteine conserved in all caspases although indirect effects on caspases can also be a component of toxicity in certain systems [214]. A switch from apoptosis to necrosis can also occur due to a drop in cellular levels of ATP caused by the failure of mitochondrial energy production by oxidants $[215,216]$. As mentioned previously ROS may provide a common link between cellular stress signals and the initiation of autophagy, and ROS accumulation has been reported to result in inactivation of the cysteine protease ATG4, which in turn causes accumulation of the ATG8-phosphoethanolamine precursor that is required for the initiation of autophagosome formation [44]. In most circumstances, the induction of an autophagic response serves as a strategy that should ensure the cell's survival [217]. Under certain conditions, however, it may also bring about cell death, although the molecular determinants that may control the switch from survival to death are still poorly defined. In fact, in response to several anticancer drugs ROS can induce autophagic cell death.

\section{Switch from Prosurvival Signaling to Cell Death Signaling}

While conditions of stress stimulate cells to mount protective responses to counteract the effect of the stress on cellular processes, if the stress remains unresolved, eventual death of the cell ensues. This raises key questions about the molecular mechanisms involved in this switch from prosurvival signaling to prodeath signaling. For example, is there a particular molecule that acts as a molecular switch? How do the duration and severity of the stress contribute to activation of this switch? As described above, in the face of exposure to 
cell stress, the cell mounts protective responses such as the heat shock response, or the unfolded protein response, in order to relieve the stress and promote survival. However, it is known that if the stress is very severe or if it is prolonged, the cell will die in spite of the activation of prosurvival signaling.

In the case of the response of cells to heat stress, the induction of Hsps does not occur if the stress is too severe and it has previously been suggested that the induction of thermotolerance, that is, Hsp expression, and of cell death is mutually exclusive events within the same cell $[87,195]$. In support of this, we have observed that in a culture exhibiting mixed responses to a stressor, that is, expression of Hsps, induction of apoptosis, and induction of necrosis, the expression of Hsps was mainly observed in the surviving cells [196]. However, a recent report suggests that this may not always be the case, as at least one agent, which induces expression of Hsps through direct activation of HSF1, induces apoptosis rather than being protective [218].

During ER stress, IRE1 may be involved in the switch between the prosurvival UPR and initiation of cell death pathways [219]. Interestingly, the three arms of the UPR are thought to be activated sequentially, with PERK being activated most rapidly, followed by ATF6 and then IRE1. This suggests that time is allowed so that PERK and ATF6 may resolve the stress, and although IRE1 also contributes to the prosurvival UPR, it ultimately terminates it by relieving the translational inhibition by inducing $\mathrm{p} 58^{\mathrm{IPK}}[20]$. If the stress has been resolved, the cell returns to normal, but if not, then apoptosis is initiated, possibly by IRE1-dependent activation of ASK1 and its downstream target JNK. However, recently it has been shown that attenuation of IRE1 can switch the adaptive UPR to apoptosis and that persistent activation of IRE1 increases cell viability upon ER stress, suggesting that the duration of IRE1 signaling may act as a switch [219].

\section{Stress Responses in Disease States}

It is currently understood that a pathological stress response is a hallmark of many common human diseases for a number of reasons. Firstly, the stress stimulus may be too strong and/or prolonged, thereby allowing insufficient time for recovery to the normal status. Secondly, a cell's ability to handle even physiological levels of stress may be altered in disease states, similarly resulting in detrimental outcomes. In the following section, we will provide some selected examples of how pathological handling of stress is one of the major underlying causes of the pathophysiological state in very different types of human diseases.

5.1. Diabetes. Loss of function or death of the pancreatic $\beta$ cells in the Islets of Langerhans in the pancreas is the major pathological feature of diabetes mellitus. The pancreatic $\beta$ cells have a highly developed secretory system, in which the ER has an integral role, enabling a rapid response to glucose stimulation by producing and releasing large amounts of insulin. Both oxidative stress and ER stress are involved in the failure of pancreatic $\beta$-cells and development of diabetes.
The reactive species which play an important role in the pathogenesis of pancreatic $\beta$-cell loss in diabetes are generated intracellularly when the $\beta$-cells are targeted by proinflammatory cytokines in autoimmune Type 1 diabetes or when exposed to a hyperglycaemic and hyperlipidaemic milieu in Type 2 diabetes. There is evidence for the participation of both $\mathrm{NO}^{\bullet}$ and ROS in the pathogenesis of $\beta$-cell death in Type 1 diabetes, whereas, for $\beta$-cell dysfunction in Type 2 diabetes, ROS are the main culprits.

Proinflammatory cytokines, including IL- $1 \beta$ (interleukin $1 \beta$ ), TNF $\alpha$ (tumor necrosis factor $\alpha$ ), and IFN $\gamma$ (interferon $\gamma$ ), released from immune cells infiltrating the pancreas in Type 1 diabetes, target the $\beta$-cells via their respective receptors [220]. They activate a multitude of signaling cascades, culminating in apoptosis of $\beta$-cells [221]. A number of steps in this chain of events affect the rate of generation of $\mathrm{NO}^{\bullet}$ and ROS. It is evident from studies in patients with diabetes and in animal models of Type 1 diabetes, that IL- $1 \beta$ is the key proinflammatory cytokine which significantly contributes to $\beta$-cell dysfunction and apoptosis in the pathogenesis of Type 1 diabetes. It does so through activation of the transcription factor NF- $\kappa \mathrm{B}$ which is responsible for the induction of iNOS and subsequent production of $\mathrm{NO}^{\bullet}[155,221]$. The production and release of IFN $\gamma$ acts synergistically with IL$1 \beta$. High concentrations of IFN $\gamma$ are required to potentiate the effects of IL-1 $\beta$ on iNOS and $\mathrm{NO}^{*}$ production [222]. NO ${ }^{\bullet}$ and ROS seem to also cross-talk with ER stress and UPR [223].

IL-1 $\beta$ also induces MnSOD (a manganese-dependent SOD isoenzyme) and this results in an increased rate of conversion of $\mathrm{O}_{2}{ }^{--}$into $\mathrm{H}_{2} \mathrm{O}_{2}$ in the mitochondria [224]. $\mathrm{Cu} / \mathrm{ZnSOD}$, the cytoplasmic isoenzyme, is unaffected by IL$1 \beta$. The profile of the effects of TNF $\alpha$ and IFN $\gamma$ alone, or in combination with IL- $1 \beta$, on MnSOD is comparable with that of their regulation of iNOS. The effects on the generation of both radicals are not only important in themselves but also affect the balance between $\mathrm{NO}^{\bullet}$ and $\mathrm{O}_{2}{ }^{\bullet-}$, and this can have significant effects on $\beta$-cell toxicity. A decrease in $\mathrm{O}_{2}^{--}$ through MnSOD may present as a protective signal through a reduction of NF- $\kappa \mathrm{B}$ activation and other components of the IL-1 $\beta$ signaling pathway [225]. On the other hand, an increased conversion rate of $\mathrm{O}_{2}{ }^{--}$into $\mathrm{H}_{2} \mathrm{O}_{2}$ by SOD is likely to increase toxicity to the $\beta$-cell with its poor enzymatic capacity for $\mathrm{H}_{2} \mathrm{O}_{2}$ inactivation $[226,227]$.

Another major proinflammatory cytokine, $\mathrm{TNF} \alpha$, is released from the infiltrating immune cells speeds up $\beta$ cell loss significantly, resulting in an accelerated progression of the disease with rapid loss of the entire pancreatic $\beta$ cell population and Islet mass. Ceramide is likely to play a significant role as a mediator of $\mathrm{O}_{2}{ }^{--}$formation in TNF $\alpha$ mediated toxicity [228], thereby explaining the dominance of ROS in the case of TNF $\alpha$ when compared with IL- $1 \beta$. Thus, with a significant contribution of TNF $\alpha$ produced by the infiltrating immune cells in Type 1 diabetes the resulting greater cytotoxicity is the result of the more pronounced ROS component of TNF $\alpha$ toxicity.

That the ROS-mediated component of cytokine toxicity primarily targets the mitochondria is shown by the fact that exposure of insulin-producing cells to IL- $1 \beta$, or to a 
cytokine mixture containing both IFN $\gamma$ and $\operatorname{TNF} \alpha$, causes mitochondrial damage, while other subcellular structures remain intact. This damage can be prevented by expression of high levels of catalase or GSH in the mitochondria, but not in the cytosol [228]. IL-1 $\beta$ toxicity, mediated through $\mathrm{NO}^{\bullet}$ and potentiated by IFN $\gamma$ and TNF $\alpha$, is likely to focus its effects in the cytoplasm. This component will presumably contribute to ER stress, which plays a significant role in dysfunction of $\beta$-cells under cytokine attack [229].

$\beta$-Cell loss in Type 2 diabetes is slower than in Type 1 diabetes, typically with a long phase of $\beta$-cell dysfunction, characterized by defective insulin secretion in response to glucose. In Type 2 diabetes, glucolipotoxicity, rather than proinflammatory cytokines, is considered to be an important contributing factor to $\beta$-cell dysfunction [230-234]. It is evident from studies on $\beta$-cells exposed to a combination of high glucose and a saturated fatty acid that $\mathrm{NO}^{\bullet}$ generation through iNOS induction does not contribute to $\beta$-cell dysfunction [235].

Increased mitochondrial metabolic flux is required in the $\beta$-cell for generation of the ATP signal for glucoseinduced insulin secretion [236] and its potentiation through fatty acids [231]. On the other hand, increased metabolic flux through the respiratory chain at high glucose and lipid concentrations should increase $\mathrm{O}_{2}{ }^{-}$formation, thereby reducing the mitochondrial membrane potential via uncoupling protein 2 [230, 237]. This should decrease metabolic flux through the respiratory chain and thus reduce $\mathrm{O}_{2}{ }^{--}$ production, thereby acting in a protective manner against ROS-induced damage, but, at the same time, attenuating nutrient-induced insulin secretion. This casts doubt on the concept that increased intra-mitochondrial generation of ROS crucially contributes to $\beta$-cell damage in Type 2 diabetes.

This interpretation is supported by the results of morphological analyses showing that insulin-producing cells exposed to the fatty acid palmitate show no signs of mitochondrial damage, but very pronounced defects of the ER [238], confirming observations of increased ER stress in response to glucolipotoxicity [235]. Thus one of the prominent targets of this free-radical-mediated toxicity might indeed be the ER.

Defects in PERK-eIF2 $\alpha$ pathways cause Wolcott-Rallison syndrome, a rare infantile-onset insulin-requiring diabetes [239] and PERK-null mice developed similar phenotypes [240]. Mice with mutated proinsulin (proinsulin-2) that cannot form a disulfide bond (Akita mice) also develop severe diabetes which is associated with the ER stress-induced cell death in pancreatic $\beta$-cells $[241,242]$. Mice deficient for p5 $8^{\mathrm{IPK}}$, which suppresses PERK-mediated phosphorylation of eIF $2 \alpha$, exhibit apoptosis of pancreatic $\beta$-cells and diabetes [243]. This suggests that the tight regulation of PERK-eIF $2 \alpha$ pathway is required for the maintenance of pancreatic $\beta$ cells. In contrast, some single nucleotide polymorphisms (SNPs) in the ORP150/GRP170 genome of Pima Indians are associated with insulin sensitivity in peripheral tissues [244]. Accordingly, overexpression of ORP150 enhances insulin sensitivity and suppresses oxidative stress but does not improve insulin secretion [245]. These findings suggest that proper functioning of the ER is important for both insulin synthesis in pancreatic $\beta$-cells and insulin sensitivity in peripheral tissues. Consistent with this hypothesis, chemical chaperones such as 4-phenylbutryic acid and tauroursodeoxycholic acid improved both insulin resistance and insulin synthesis $[171,246]$.

5.2. Parkinson's Disease. Neurodegenerative diseases are characterized by the loss of subsets of neurons. The course of these diseases can last decades, with the accumulation of neuronal loss causing progressively worse symptoms. Postmortem tissue is usually obtained from end-stage patients, at which time many of the evidences regarding the events preceding cell death are long gone. However, there is substantial and growing evidence for the activation of stress responses in neurons in all of the common neurodegenerative diseases. This suggests that when neurons are exposed to stress, they counteract with activation of one or more protective stress responses; however, eventually the neurons are unable to cope and one-by-one they are lost as the disease progresses. There is a growing recognition that protein misfolding and impairment of protein handling play a key role in neuronal cell death in neurodegenerative diseases [153].

As an example of stress responses and stress-induced cell death in neurodegenerative disease, we will describe the evidence pertaining to Parkinson's disease. Parkinson's disease is the second most common neurodegenerative disease, affecting mainly people over 55 years and causing progressively worsening motor impairment. It is characterized pathologically by the degeneration of midbrain dopaminergic neurons in the substantia nigra pars compacta and the presence of proteinaceous intracytoplasmic inclusions (Lewy bodies) within the surviving neurons.

The molecular mechanisms that initiate dopaminergic neuron loss in Parkinson's disease are not known. Evidence from various sources suggest that environmental toxins, genetic predisposition, and aging are important factors in the onset and progression of the disease [247-249]. Insecticides such as rotenone and the mitochondrial toxin 1Methyl-4-phenyl-1, 2,3,6-tetrahydropyridine (MPTP) cause dopaminergic neuronal loss in animal models and have been implicated in Parkinson's disease itself [250, 251]. To date, mutations in at least 13 PARK genes have been linked to the pathogenesis of familial Parkinson's disease which include mutations in genes that encode the proteins $\alpha$ synuclein, parkin, PTEN-induced kinase 1 (PINK1), DJ1, leucine-rich repeat kinase2 (LRRK2), Omi/Htra2, and ubiquitin carboxy-terminal hydrolase L1 (UCHL1) [252]. Of these, $\alpha$-synuclein (along with chaperone proteins and ubiquitin) is a major component of Lewy bodies. Parkin and UCHL1 are linked to the ubiquitin-proteasome system that degrades damaged or misfolded proteins [253]. In addition, several of these genes, including parkin, PINK1, DJ-1, and Omi/Htra2 are linked to the mitochondria and may have roles in mitochondrial function and resistance to oxidative stress [254].

Mutations in PARK genes, as well as toxins that specifically target dopaminergic neurons, have been strongly 
linked to the activation of stress responses in dopaminergic neurons. For example, mitochondrial dysfunction due to mutations in certain PARK genes or to environmental toxins is linked with impairment of mitochondrial complex I which causes oxidative stress in affected cells. It has long been known that oxidative stress is a feature of Parkinson's disease and it is observed in experimental models of Parkinson's disease and in tissues from individuals with sporadic forms of the disease [255].

Most of the evidence regarding activation of the heat shock response in Parkinson's disease come from models. Targeted overexpression of $\alpha$-synuclein in mouse substantia nigra causes an increase in the expression of Hsp27, Hsp40, and Hsp70 [256, 257] and elevations in Hsp27 are observed in in vitro models of Parkinson's disease using the neurotoxin 6-hydroxdopamine [196]. Recent findings from Parkinsonian patients have described that DnaJB6 is present in the core of Lewy bodies and is also upregulated in astrocytes [258]. DnaJB6 is one of the Hsp40 chaperones, which stabilizes the interactions of Hsp70s with their substrate proteins. In vitro and in vivo models of Parkinson's disease demonstrate that overexpression of Hsps prevents $\alpha$-synuclein aggregation as well as dopaminergic neuronal cell death due to $\alpha$-synuclein and Parkinson mimetic toxins [216, 237, 239-242]. Interestingly, the inducibility of Hsps decreases with aging, which may contribute to the inability of aged neurons to fully protect themselves from stresses such as protein misfolding, aggregation, and oxidative stress [259].

Activation of the UPR has been reported in postmortem brain tissue from patients with Parkinson's disease. Specifically, phosphorylated PERK and phosphorylated eIF $2 \alpha$ have been detected in dopaminergic neurons in the substantia nigra of Parkinson's disease patients [260]. Phospho-PERK immunoreactivity was colocalized with increased $\alpha$-synuclein immunoreactivity in dopaminergic neurons [260]. Supporting evidences from in vitro models of Parkinson's disease show that 6-hydroxydopamine and 1-methyl-4-phenyl-1,2,3,6-tetrahydropyridine $\left(\mathrm{MPP}^{+}\right)$ (Parkinson mimetic drugs) trigger ER stress in dopaminergic neurons $[261,262]$. Furthermore, neuronal cultures from PERK knockout mice display an increased sensitivity to 6hydroxydopamine [262], while a null mutation in CHOP results in a reduction in 6-hydroxydopamine-induced apoptosis in vivo [263]. However, protection was not observed in the chronic MPTP model, despite robust expression of CHOP [263].

The information from models, the genetic information, as well as analysis of postmortem tissue, when taken together, strongly connects the induction of stress responses with the loss of dopaminergic neurons in Parkinson's disease. It is likely that the induction of stress responses is the neurons attempts at protection, which eventually fail with neuronal cell death being the inevitable outcome. Interestingly, these observations are mirrored in research findings of other common neurodegenerative diseases, including Alzheimer's disease and Huntington's disease, indicating the important role for protein misfolding, aggregation and formation of protein inclusions in these chronic diseases [153].
5.3. Myocardial Infarction. Cardiovascular disease (CVD), a group of disorders of the heart and the vasculature, includes high blood pressure, coronary heart disease, congestive heart failure, stroke, and congenital heart defects. Apoptotic cell death is a fundamental process in the morphogenesis of the developing heart $[264,265]$. Until recently the classical view was that necrosis was the major mode of cardiomyocyte death during CVD. However, accumulating in vitro and in vivo studies provides compelling evidence that terminally differentiated cardiomyocytes, can and do undergo apoptosis [266]. Apoptosis has important pathophysiological consequences, contributing to the loss and functional abnormalities of the myocardium. Cardiomyocyte apoptosis has been reported in a variety of cardiovascular diseases, including myocardial infarction, end-stage heart failure, arrhythmogenic right ventricular dysplasia, and adriamycininduced cardiomyopathy [267]. Animal models have been instrumental in establishing the occurrence of cardiomyocyte apoptosis and in the elucidation of the apoptotic mechanisms. Features of myocyte apoptosis were first reported in rabbit and rat heart models of MI or ischemia/reperfusion injury $[268,269]$. Since these pioneering studies, apoptosis has been repeatedly observed in the injured human heart [270-274]. Due to its sporadic occurrence and the prompt clearance of apoptotic cells by phagocytosis, apoptosis in diseased tissue is grossly underestimated.

Oxidative damage mediated by free radicals is a contributing factor to ischemia/reperfusion-induced injury in cardiomyocytes [275-278]. Plasma and pericardial fluid obtained from patients with end stage heart failure have increased levels of thiobarbituric acid reactive substances, a commonly used marker of ROS production [279, 280]. Reperfusion is associated with a burst of ROS generated via the mitochondrial respiratory chain, where partial reduction of ubiquinone forms ubisemiquinone combine with oxygen to form $\mathrm{O}_{2}{ }^{--}$radicals [281]. High levels of ROS can lead to mitochondrial damage and dysfunction [282] and can induce apoptosis in cardiac myocytes $[275,276]$.

In addition, enhanced levels of the heat shock response and UPR have been demonstrated in animal models of myocardial infarction, and overexpression of either Hsps or GRPs enhanced tolerance against ischemia/reperfusion injury in these models $[283,284]$. Although Hsps may work upstream of caspase-3 but downstream of cytochrome $c$ release [285], GRPs likely contribute to the maintenance of intracellular $\mathrm{Ca}^{2+}$ homeostasis [284]. Similarly, overexpression of sarco (endo) plasmic reticulum $\mathrm{Ca}^{2+-}$ ATPase (SERCA), which regulates intracellular $\mathrm{Ca}^{2+}$ homeostasis, improved postischemic cardiac function and decreased myocardial infarction [286].

5.4. Cancer. Since tissue homeostasis is the result of a subtle balance between proliferation on one side and cell death on the other side, changes in the rate of cell death can contribute to either the loss or gain of tissue [22]. For example, too little cell death can contribute to tumor formation and is considered to be one of the hallmarks of human cancers $[287,288]$. Some oncogenic mutations 
block cell death pathways creating a permissive environment for genetic instability and resulting in the accumulation of gene mutations leading to tumor initiation and progression [289]. Also, evasion of cell death promotes resistance to immune-based destruction, facilitates growth factor- or hormone-independent survival, and supports anchorageindependent survival during metastasis [288]. In addition, defects in cell death programs may confer resistance to cytotoxic therapies that are currently used in the clinic for the treatment of cancer such as chemotherapy, irradiation, or immunotherapy, since the response of cancer cells to these treatment approaches is, to a large extent, due to their ability to undergo cell death in response to cytotoxic stimuli [290292].

In principle, the signaling to apoptosis can be blocked in cancers by loss or defective function of proapoptotic molecules, aberrantly high expression of antiapoptotic proteins, and/or by the relative dominance of cell survival signaling pathways. For example, impaired death receptor expression or function has been reported in a variety of human cancers. Reduced expression of CD95 was found in drug-resistant leukemia or neuroblastoma cells, indicating that intact signaling via CD95 is linked to drug response [293, 294]. CD95 mutations have been detected in both hematological malignancies and various solid tumors [295300]. It is interesting to note that both agonistic TRAIL receptors, that is, TRAIl-R1 and TRAIL-R2, are located on chromosome $8 \mathrm{p}$, a region that is frequently lost in cancers due to heterozygosity [301, 302]. Further, a larger range of antiapoptotic proteins are reported to be expressed at high levels in malignant versus nonmalignant tissue, including death domain-containing proteins that interfere with activation of caspase- 8 at the death receptor level such as cellular FLICE-Inhibitory Protein (cFLIP) and phosphoprotein enriched in diabetes/phosphoprotein enriched in astrocytes-15kDa (PED/PEA-15) [303], anti-apoptotic $\mathrm{Bcl}-2$ family proteins such as Bcl-2, Bcl-X $\mathrm{X}_{L}$ and $\mathrm{Mcl}-1$ [31] and IAPs, including XIAP, cIAP1, cIAP2, survivin and livin [304]. Alternatively, apoptosis regulators with proapoptotic functions have been reported to be lost, mutated or epigenetically silenced in cancers. Examples include epigenetic loss or homo- or heterozygous genomic deletions of caspase-8 [305], single nucleotide substitution or frameshift mutations of the bax gene in mismatch repairdeficient colon cancer or hematopoetic malignancies [306, 307], and deletion or epigenetic silencing of the bim gene [308-310].

It is also now generally accepted that the majority of tumors, due to poor vascularisation of the tumor mass, experience stressful conditions in the tumor microenvironment, including low oxygen supply, nutrient deprivation, and $\mathrm{pH}$ changes. These conditions activate a range of cellular stressresponse pathways, including the UPR. Recent studies have shown that the UPR plays an important role in tumorigenesis [311-315]. Activation of at least one branch of the UPR has been reported in a number of cancers and many ER chaperones and UPR target genes show increased expression in human tumor samples. Although activation of the UPR has been reported in a variety of human cancers, the role of UPR in different forms of cancer is not yet fully characterized.

At present it is unclear how tumor cells adapt to longterm ER stress in vivo-whether the protective elements of the response are enhanced, the destructive components suppressed, or if the compromised apoptotic machinery is sufficient to protect them from UPR-induced apoptosis. Given that the UPR can trigger prosurvival and proapoptotic signals, it is important to understand how modulation of the UPR alters the balance between these processes and contributes to carcinogenesis in different cell types. The upregulation of UPR in cancers may be beneficial for the tumor cells by increasing the protein folding capacity and prolonging life.

Moreover, altered redox status can promote tumor initiation and progression by blunting cell death pathways. For example, a pro-oxidant intracellular milieu has been linked to carcinogenesis and tumor promotion. To this end, increased signaling via the PI3K/Akt pathway has been shown to result in enhanced intracellular ROS generation [316]. Similarly, cancer cells that constitutively express oncogenic Ras have been reported to harbor higher intracellular levels of $\mathrm{O}_{2}{ }^{--}$and to be resistant to drug-induced apoptosis [317].

Hsps, including Hsp90, Hsp70, and Hsp27, are expressed at increased levels in many solid tumors and haematological malignancies. Since various oncogenic proteins that are critically required for the malignant transformation of cells, for example, Ras, Akt, and HER2, are client proteins of Hsp90, elevated levels of Hsp90 favor tumor initiation and promotion [318]. Similarly, the expression of Hsp27 and Hsp70 is abnormally high in cancers [319]. These chaperones participate in carcinogenesis and in cell death resistance by blocking key effector molecules of the apoptotic machinery at the pre- and post-mitochondrial level [319]. Thus, targeting Hsps, for example, with chemical inhibitors, is currently under investigation as anticancer strategy [318].

Error-prone repair or complete failure to repair DNA damage as well as inherited or acquired defects in maintenance systems of the mammalian genome can lead to mutations [185]. In addition, such deficiencies in the DNA damage response contribute substantially to carcinogenesis and promote the progression and treatment resistance of cancer [185].

\section{Summary and Future Perspectives}

Cellular stress responses are an integral part of normal physiology to either ensure the cell's survival or alternatively to eliminate damaged or unwanted cells. Several distinct stress responses can be distinguished, among them the heat shock, unfolded protein, DNA damage, and oxidative stress responses. Despite individual signaling components, these different stress responses can eventually fuel into common cell death effector mechanisms, if the cell is unable to cope with the stress. Whether or not cellular stress triggers cell death or cell survival programs is determined by a set of different factors, among them the initial stress stimulus, cell 
type, and environmental factors. Because aberrant cellular stress responses are tightly linked to many common human diseases, a better understanding of the underlying molecular mechanisms is expected to enable us to interfere with these processes, for example, to switch such response from cell death into survival programs or vice versa, depending on the desired outcome. In addition, new insights into the mechanistic basis of stress responses will open new perspectives for the development of molecular targeted treatment approaches and thus have a great potential for drug discovery.

\section{Acknowledgments}

The authors are grateful to Drs. Sandra Healy and Sanjeev Gupta for their suggestions and comments on this manuscript. Fulda's group is supported by grants from the Deutsche Forschungsgemeinschaft, the Bundesministerium für Bildung und Forschung, the Deutsche Krebshilfe, the EU (ApopTrain, APO-SYS), the Wilhelm Sander Stiftung, the Else-Kröner-Fresenius Stiftung, the Novartis Stiftung für therapeutische Forschung, and IAP6/18. Research in Samali and Gorman groups is financially supported by Science Foundation Ireland under Grant nos. 09/RFP/BMT2153, 09/RFP/BIC2371, and 05/IN3/B851 as well as grants from Health Research Board of Ireland (HRA/2009/59) and the Breast Cancer Campaign.

\section{References}

[1] R. A. Lockshin and Z. Zakeri, "Programmed cell death and apoptosis: origins of the theory," Nature Reviews Molecular Cell Biology, vol. 2, no. 7, pp. 545-550, 2001.

[2] R. A. Lockshin and C. M. Williams, "Programmed cell death-I. Cytology of degeneration in the intersegmental muscles of the Pernyi silkmoth," Journal of Insect Physiology, vol. 11, no. 2, pp. 123-133, 1965.

[3] R. A. Lockshin and C. M. Williams, "Programmed cell death-IV. The influence of drugs on the breakdown of the intersegmental muscles of silkmoths," Journal of Insect Physiology, vol. 11, no. 6, pp. 803-809, 1965.

[4] R. A. Lockshin and C. M. Williams, "Programmed cell death-V. Cytolytic enzymes in relation to the breakdown of the intersegmental muscles of silkmoths," Journal of Insect Physiology, vol. 11, no. 7, pp. 831-844, 1965.

[5] B. M. Pützer, "E2F1 death pathways as targets for cancer therapy," Journal of Cellular and Molecular Medicine, vol. 11, no. 2, pp. 239-251, 2007.

[6] J. L. V. Reeve, A. M. Duffy, T. O'Brien, and A. Samali, “Don't lose heart - therapeutic value of apoptosis prevention in the treatment of cardiovascular disease," Journal of Cellular and Molecular Medicine, vol. 9, no. 3, pp. 609-622, 2005.

[7] A. Samali, "A tribute to professor Richard A. Lockshin on his 70th birthday," Journal of Cellular and Molecular Medicine, vol. 11, no. 6, pp. 1210-1211, 2007.

[8] Z. Zakeri, W. Bursch, M. Tenniswood, and R. A. Lockshin, "Cell death: programmed, apoptosis, necrosis, or other?" Cell Death and Differentiation, vol. 2, no. 2, pp. 87-96, 1995.

[9] J. F. Kerr, A. H. Wyllie, and A. R. Currie, "Apoptosis: a basic biological phenomenon with wide-ranging implications in tissue kinetics," British Journal of Cancer, vol. 26, no. 4, pp. 239-257, 1972.

[10] J. F. Kerr, "Shrinkage necrosis: a distinct mode of cellular death," Journal of Pathology, vol. 105, no. 1, pp. 13-20, 1971.

[11] B. F. Trump, P. J. Goldblatt, and R. E. Stowell, "An electron microscopic study of early cytoplasmic alterations in hepatic parenchymal cells of mouse liver during necrosis in vitro (autolysis)," Laboratory Investigation, vol. 11, pp. 986-1015, 1962.

[12] M. Berenbom, P. I. Chang, H. E. Betz, and R. E. Stowell, "Chemical and enzymatic changes associated with mouse liver necrosis in vitro," Cancer Research, vol. 15, no. 1, pp. $1-5,1955$.

[13] B. C. Trauth, C. Klas, A. M. J. Peters, et al., "Monoclonal antibody-mediated tumor regression by induction of apoptosis," Science, vol. 245, no. 4915, pp. 301-305, 1989.

[14] J. Yang, X. Liu, K. Bhalla, et al., "Prevention of apoptosis by Bcl-2: release of cytochrome c from mitochondria blocked," Science, vol. 275, no. 5303, pp. 1129-1132, 1997.

[15] D. L. Vaux, S. Cory, and J. M. Adams, "Bcl-2 gene promotes haemopoietic cell survival and cooperates with c-myc to immortalize pre-B cells," Nature, vol. 335, no. 6189, pp. 440442, 1988.

[16] D. Hockenbery, G. Nunez, C. Milliman, R. D. Schreiber, and S. J. Korsmeyer, " $\mathrm{Bcl}-2$ is an inner mitochondrial membrane protein that blocks programmed cell death," Nature, vol. 348, no. 6299, pp. 334-336, 1990.

[17] N. Itoh, S. Yonehara, A. Ishii, et al., "The polypeptide encoded by the cDNA for human cell surface antigen fas can mediate apoptosis," Cell, vol. 66, no. 2, pp. 233-243, 1991.

[18] J. Yuan, S. Shaham, S. Ledoux, H. M. Ellis, and H. R. Horvitz, "The C. elegans cell death gene ced-3 encodes a protein similar to mammalian interleukin- $1 \beta$-converting enzyme," Cell, vol. 75, no. 4, pp. 641-652, 1993.

[19] R. M. Kluck, E. Bossy-Wetzel, D. R. Green, and D. D. Newmeyer, "The release of cytochrome c from mitochondria: a primary site for Bcl- 2 regulation of apoptosis," Science, vol. 275, no. 5303, pp. 1132-1136, 1997.

[20] E. Szegezdi, S. E. Logue, A. M. Gorman, and A. Samali, "Mediators of endoplasmic reticulum stress-induced apoptosis," EMBO Reports, vol. 7, no. 9, pp. 880-885, 2006.

[21] A. Samali, B. Zhivotovsky, D. Jones, S. Nagata, and S. Orrenius, "Apoptosis: cell death defined by caspase activation," Cell Death and Differentiation, vol. 6, no. 6, pp. 495-496, 1999.

[22] R. A. Lockshin and Z. Zakeri, "Cell death in health and disease," Journal of Cellular \& Molecular Medicine, vol. 11, no. 6, pp. 1214-1224, 2007.

[23] A. Samali, A. M. Gorman, and T. G. Cotter, "Apoptosisthe story so far," Experientia, vol. 52, no. 10-11, pp. 933-941, 1996.

[24] R. T. Bree, C. Stenson-Cox, M. Grealy, L. Byrnes, A. M. Gorman, and A. Samali, "Cellular longevity: role of apoptosis and replicative senescence," Biogerontology, vol. 3, no. 4, pp. 195-206, 2002.

[25] A. Degterev, M. Boyce, and J. Yuan, "A decade of caspases," Oncogene, vol. 22, no. 53, pp. 8543-8567, 2003.

[26] A. Ashkenazi, "Targeting the extrinsic apoptosis pathway in cancer," Cytokine and Growth Factor Reviews, vol. 19, no. 3-4, pp. 325-331, 2008.

[27] A. Samali, "Apoptosis: a mapped path to cell death," Journal of Cellular and Molecular Medicine, vol. 11, no. 6, pp. 12121213, 2007. 
[28] G. Kroemer, L. Galluzzi, and C. Brenner, "Mitochondrial membrane permeabilization in cell death," Physiological Reviews, vol. 87, no. 1, pp. 99-163, 2007.

[29] H. Zou, Y. Li, X. Liu, and X. Wang, "An APAf-1 · cytochrome C multimeric complex is a functional apoptosome that activates procaspase-9," Journal of Biological Chemistry, vol. 274, no. 17, pp. 11549-11556, 1999.

[30] E. C. LaCasse, D. J. Mahoney, H. H. Cheung, S. Plenchette, S. Baird, and R. G. Korneluk, "IAP-targeted therapies for cancer," Oncogene, vol. 27, no. 48, pp. 6252-6275, 2008.

[31] J. M. Adams and S. Cory, "The Bcl-2 apoptotic switch in cancer development and therapy," Oncogene, vol. 26, no. 9, pp. 1324-1337, 2007.

[32] A. Letai, M. C. Bassik, L. D. Walensky, M. D. Sorcinelli, S. Weiler, and S. J. Korsmeyer, "Distinct BH3 domains either sensitize or activate mitochondrial apoptosis, serving as prototype cancer therapeutics," Cancer Cell, vol. 2, no. 3, pp. 183-192, 2002.

[33] L. Chen, S. N. Willis, A. Wei, et al., "Differential targeting of prosurvival Bcl-2 proteins by their $\mathrm{BH} 3$-only ligands allows complementary apoptotic function," Molecular Cell, vol. 17, no. 3, pp. 393-403, 2005.

[34] S. N. Willis, J. I. Fletcher, T. Kaufmann, et al., "Apoptosis initiated when $\mathrm{BH} 3$ ligands engage multiple Bcl-2 homologs, not Bax or Bak," Science, vol. 315, no. 5813, pp. 856-859, 2007.

[35] E. Varfolomeev and D. Vucic, "(Un)expected roles of c-IAPs in apoptotic and $\mathrm{NF} \kappa \mathrm{B}$ signaling pathways," Cell Cycle, vol. 7, no. 11, pp. 1511-1521, 2008.

[36] E.-L. Eskelinen, "New insights into the mechanisms of macroautophagy in Mammalian cells," International Review of Cell and Molecular Biology, vol. 266, pp. 207-247, 2008.

[37] X. H. Liang, S. Jackson, M. Seaman, et al., "Induction of autophagy and inhibition of tumorigenesis by beclin 1 ," Nature, vol. 402, no. 6762, pp. 672-676, 1999.

[38] Y. Ohsumi, "Molecular dissection of autophagy: two ubiquitin-like systems," Nature Reviews Molecular Cell Biology, vol. 2, no. 3, pp. 211-216, 2001.

[39] Y. Kabeya, N. Mizushima, T. Ueno, et al., "LC3, a mammalian homologue of yeast Apg8p, is localized in autophagosome membranes after processing," EMBO Journal, vol. 19, no. 21, pp. 5720-5728, 2000.

[40] J. J. Lum, D. E. Bauer, M. Kong, et al., "Growth factor regulation of autophagy and cell survival in the absence of apoptosis," Cell, vol. 120, no. 2, pp. 237-248, 2005.

[41] U. B. Pandey, Z. Nie, Y. Batlevi, et al., "HDAC6 rescues neurodegeneration and provides an essential link between autophagy and the UPS," Nature, vol. 447, no. 7146, pp. 859863, 2007.

[42] M. Høyer-Hansen, L. Bastholm, P. Szyniarowski, et al., "Control of macroautophagy by calcium, calmodulin-dependent kinase kinase- $\beta$, and Bcl-2," Molecular Cell, vol. 25, no. 2, pp. 193-205, 2007.

[43] M. Ogata, S.-I. Hino, A. Saito, et al., "Autophagy is activated for cell survival after endoplasmic reticulum stress," Molecular \& Cellular Biology, vol. 26, no. 24, pp. 9220-9231, 2006.

[44] R. Scherz-Shouval, E. Shvets, E. Fass, H. Shorer, L. Gil, and Z. Elazar, "Reactive oxygen species are essential for autophagy and specifically regulate the activity of Atg4," EMBO Journal, vol. 26, no. 7, pp. 1749-1760, 2007.

[45] A. Nakai, O. Yamaguchi, T. Takeda, et al., "The role of autophagy in cardiomyocytes in the basal state and in response to hemodynamic stress," Nature Medicine, vol. 13, no. 5, pp. 619-624, 2007.

[46] R. S. Decker and K. Wildenthal, "Lysosomal alterations in hypoxic and reoxygenated hearts. I. Ultrastructural and cytochemical changes," American Journal of Pathology, vol. 98, no. 2, pp. 425-444, 1980.

[47] S. Khan, F. Salloum, A. Das, L. Xi, G. W. Vetrovec, and R. C. Kukreja, "Rapamycin confers preconditioning-like protection against ischemia-reperfusion injury in isolated mouse heart and cardiomyocytes," Journal of Molecular and Cellular Cardiology, vol. 41, no. 2, pp. 256-264, 2006.

[48] S. Shimizu, T. Kanaseki, N. Mizushima, et al., "Role of Bcl-2 family proteins in a non-apoptopic programmed cell death dependent on autophagy genes," Nature Cell Biology, vol. 6, no. 12, pp. 1221-1228, 2004.

[49] L. Yu, A. Alva, H. Su, et al., "Regulation of an ATG7-beclin 1 program of autophaglic cell death by caspase-8," Science, vol. 304, no. 5676, pp. 1500-1502, 2004.

[50] E. Ullman, Y. Fan, M. Stawowczyk, H. M. Chen, Z. Yue, and W. X. Zong, "Autophagy promotes necrosis in apoptosisdeficient cells in response to ER stress," Cell Death and Differentiation, vol. 15, no. 2, pp. 422-425, 2008.

[51] P. Boya, R. A. González-Polo, N. Casares, et al., "Inhibition of macroautophagy triggers apoptosis," Molecular \& Cellular Biology, vol. 25, no. 3, pp. 1025-1040, 2005.

[52] S. Pattingre, A. Tassa, X. Qu, et al., "Bcl-2 antiapoptotic proteins inhibit Beclin 1-dependent autophagy," Cell, vol. 122, no. 6, pp. 927-939, 2005.

[53] U. Akar, A. Chaves-Reyez, M. Barria, et al., "Silencing of Bcl-2 expression by small interfering RNA induces autophagic cell death in MCF-7 breast cancer cells," Autophagy, vol. 4, no. 5, pp. 669-679, 2008.

[54] S. Erlich, L. Mizrachy, O. Segev, et al., "Differential interactions between Beclin 1 and Bcl-2 family members," Autophagy, vol. 3, no. 6, pp. 561-568, 2007.

[55] M. C. Maiuri, A. Criollo, E. Tasdemir, et al., "BH3-only proteins and $\mathrm{BH} 3$ mimetics induce autophagy by competitively disrupting the interaction between Beclin 1 and $\mathrm{Bcl}-2 / \mathrm{Bcl}-$ XL," Autophagy, vol. 3, no. 4, pp. 374-376, 2007.

[56] M. C. Maiuri, G. Le Toumelin, A. Criollo, et al., "Functional and physical interaction between $\mathrm{Bcl}-\mathrm{X}_{\mathrm{L}}$ and a $\mathrm{BH}$-like domain in Beclin-1," EMBO Journal, vol. 26, no. 10, pp. 2527-2539, 2007.

[57] A. Oberstein, P. D. Jeffrey, and Y. Shi, "Crystal structure of the $\mathrm{Bcl}-\mathrm{X}_{\mathrm{L}}$-beclin 1 peptide complex: beclin 1 is a novel $\mathrm{BH} 3$ only protein," Journal of Biological Chemistry, vol. 282, no. 17, pp. 13123-13132, 2007.

[58] N. Vanlangenakker, T. V. Berghe, D. V. Krysko, N. Festjens, and P. Vandenabeele, "Molecular mechanisms and pathophysiology of necrotic cell death," Current Molecular Medicine, vol. 8, no. 3, pp. 207-220, 2008.

[59] P. Golstein and G. Kroemer, "Cell death by necrosis: towards a molecular definition," Trends in Biochemical Sciences, vol. 32, no. 1, pp. 37-43, 2007.

[60] J. Hitomi, D. E. Christofferson, A. Ng, et al., "Identification of a molecular signaling network that regulates a cellular necrotic cell death pathway," Cell, vol. 135, no. 7, pp. 13111323, 2008.

[61] W. X. Zong, D. Ditsworth, D. E. Bauer, Z. Q. Wang, and C. B. Thompson, "Alkylating DNA damage stimulates a regulated form of necrotic cell death," Genes and Development, vol. 18, no. 11, pp. 1272-1282, 2004. 
[62] M. Ankarcrona, J. M. Dypbukt, E. Bonfoco, et al., "Glutamate-induced neuronal death: a succession of necrosis or apoptosis depending on mitochondrial function," Neuron, vol. 15, no. 4, pp. 961-973, 1995.

[63] C. Zhu, X. Wang, F. Xu, et al., "The influence of age on apoptotic and other mechanisms of cell death after cerebral hypoxia-ischemia," Cell Death and Differentiation, vol. 12, no. 2, pp. 162-176, 2005.

[64] N. Festjens, T. Vanden Berghe, S. Cornelis, and P. Vandenabeele, "RIP1, a kinase on the crossroads of a cell's decision to live or die," Cell Death and Differentiation, vol. 14, no. 3, pp. 400-410, 2007.

[65] E. Meylan and J. Tschopp, “The RIP kinases: crucial integrators of cellular stress," Trends in Biochemical Sciences, vol. 30, no. 3, pp. 151-159, 2005.

[66] N. Holler, R. Zaru, O. Micheau, et al., "Fas triggers an alternative, caspase-8-independent cell death pathway using the kinase RIP as effector molecule," Nature Immunology, vol. 1, no. 6, pp. 489-495, 2000.

[67] F. K. Chan, J. Shisler, J. G. Bixby, et al., "A role for tumor necrosis factor receptor-2 and receptor-interacting protein in programmed necrosis and antiviral responses," Journal of Biological Chemistry, vol. 278, no. 51, pp. 51613-51621, 2003.

[68] Y. Ma, V. Temkin, H. Liu, and R. M. Pope, "NF- $\kappa$ B protects macrophages from lipopolysaccharide-induced cell death: the role of caspase 8 and receptor-interacting protein," Journal of Biological Chemistry, vol. 280, no. 51, pp. 4182741834, 2005.

[69] A. Degterev, Z. Huang, M. Boyce, et al., "Chemical inhibitor of nonapoptotic cell death with therapeutic potential for ischemic brain injury," Nature Chemical Biology, vol. 1, no. 2, pp. 112-119, 2005.

[70] A. Degterev, J. Hitomi, M. Germscheid, et al., "Identification of RIP1 kinase as a specific cellular target of necrostatins," Nature Chemical Biology, vol. 4, no. 5, pp. 313-321, 2008.

[71] Z. You, S. I. Savitz, J. Yang, et al., "Necrostatin-1 reduces histopathology and improves functional outcome after controlled cortical impact in mice," Journal of Cerebral Blood Flow and Metabolism, vol. 28, no. 9, pp. 1564-1573, 2008.

[72] Y. S. Cho, S. Challa, D. Moquin, et al., "Phosphorylationdriven assembly of the RIP1-RIP3 complex regulates programmed necrosis and virus-induced inflammation," Cell, vol. 137, no. 6, pp. 1112-1123, 2009.

[73] S. He, L. Wang, L. Miao, et al., "Receptor interacting protein kinase-3 determines cellular necrotic response to TNF- $\alpha$," Cell, vol. 137, no. 6, pp. 1100-1111, 2009.

[74] D. W. Zhang, J. Shao, J. Lin, et al., "RIP3, an energy metabolism regulator that switches TNF-induced cell death from apoptosis to necrosis," Science, vol. 325, no. 5938, pp. 332-336, 2009.

[75] K. Schulze-Osthoff, A. C. Bakker, B. Vanhaesebroeck, R. Beyaert, W. A. Jacob, and W. Fiers, "Cytotoxic activity of tumor necrosis factor is mediated by early damage of mitochondrial functions. Evidence for the involvement of mitochondrial radical generation," Journal of Biological Chemistry, vol. 267, no. 8, pp. 5317-5323, 1992.

[76] M. Kalai, G. Van Loo, T. Vanden Berghe, et al., "Tipping the balance between necrosis and apoptosis in human and murine cells treated with interferon and dsRNA," Cell Death and Differentiation, vol. 9, no. 9, pp. 981-994, 2002.

[77] F. Van Herreweghe, J. Mao, F. W. R. Chaplen, et al., "Tumor necrosis factor-induced modulation of glyoxalase I activities through phosphorylation by PKA results in cell death and is accompanied by the formation of a specific methylglyoxalderived AGE," Proceedings of the National Academy of Sciences of the United States of America, vol. 99, no. 2, pp. 949-954, 2002.

[78] R. G. Hansford and D. Zorov, "Role of mitochondrial calcium transport in the control of substrate oxidation," Molecular \& Cellular Biochemistry, vol. 184, no. 1-2, pp. 359-369, 1998.

[79] B. T. Chua, K. Guo, and P. Li, "Direct cleavage by the calcium-activated protease calpain can lead to inactivation of caspases," Journal of Biological Chemistry, vol. 275, no. 7, pp. 5131-5135, 2000.

[80] A. Samali, H. Nordgren, B. Zhivotovsky, E. Peterson, and S. Orrenius, "A comparative study of apoptosis and necrosis in HepG2 cells: oxidant-induced caspase inactivation leads to necrosis," Biochemical and Biophysical Research Communications, vol. 255, no. 1, pp. 6-11, 1999.

[81] C. R. Weston and R. J. Davis, "The JNK signal transduction pathway," Current Opinion in Cell Biology, vol. 19, no. 2, pp. 142-149, 2007.

[82] N. D. Perkins and T. D. Gilmore, "Good cop, bad cop: the different faces of NF- $\kappa \mathrm{B}$," Cell Death and Differentiation, vol. 13, no. 5, pp. 759-772, 2006.

[83] S. Lindquist, “The heat-shock response," Annual Review of Biochemistry, vol. 55, pp. 1151-1191, 1986.

[84] E. A. Craig, "The heat shock response," CRC Critical Reviews in Biochemistry, vol. 18, no. 3, pp. 239-280, 1985.

[85] A. Samali and S. Orrenius, "Heat shock proteins: regulators of stress response and apoptosis," Cell Stress and Chaperones, vol. 3, no. 4, pp. 228-236, 1998.

[86] A. Samali and T. G. Cotter, "Heat shock proteins increase resistance to apoptosis," Experimental Cell Research, vol. 223, no. 1, pp. 163-170, 1996.

[87] A. Samali, C. I. Holmberg, L. Sistonen, and S. Orrenius, "Thermotolerance and cell death are distinct cellular responses to stress: dependence on heat shock proteins," FEBS Letters, vol. 461, no. 3, pp. 306-310, 1999.

[88] G. C. Li and Z. Werb, "Correlation between synthesis of heat shock proteins and development of thermotolerance in Chinese hamster fibroblasts," Proceedings of the National Academy of Sciences of the United States of America, vol. 79, no. 10, pp. 3218-3222, 1982.

[89] R. I. Morimoto, P. E. Kroeger, and J. J. Cotto, "The transcriptional regulation of heat shock genes: a plethora of heat shock factors and regulatory conditions," EXS, vol. 77, pp. 139-163, 1996.

[90] L. Pirkkala, P. Nykänen, and L. Sistonen, "Roles of the heat shock transcription factors in regulation of the heat shock response and beyond," FASEB Journal, vol. 15, no. 7, pp. 1118-1131, 2001.

[91] A. Shabtay and Z. Arad, "Reciprocal activation of HSF1 and HSF3 in brain and blood tissues: is redundancy developmentally related?" American Journal of Physiology, vol. 291, no. 3, pp. R566-R572, 2006.

[92] D. R. McMillan, X. Xiao, L. Shao, K. Graves, and I. J. Benjamin, "Targeted disruption of heat shock transcription factor 1 abolishes thermotolerance and protection against heat-inducible apoptosis," Journal of Biological Chemistry, vol. 273, no. 13, pp. 7523-7528, 1998.

[93] X. Xiao, X. Zuo, A. A. Davis, et al., "HSF1 is required for extra-embryonic development, postnatal growth and protection during inflammatory responses in mice," $E M B O$ Journal, vol. 18, no. 21, pp. 5943-5952, 1999. 
[94] Y. Zhang, L. Huang, J. Zhang, D. Moskophidis, and N. F. Mivechi, "Targeted disruption of hsf1 leads to lack of thermotolerance and defines tissue-specific regulation for stress-inducible hsp molecular chaperones," Journal of Cellular Biochemistry, vol. 86, no. 2, pp. 376-393, 2002.

[95] P. Östling, J. K. Björk, P. Roos-Mattjus, V. Mezger, and L. Sistonen, "Heat Shock Factor 2 (HSF2) contributes to inducible expression of hsp genes through interplay with HSF1," Journal of Biological Chemistry, vol. 282, no. 10, pp. 7077-7086, 2007.

[96] I. Shamovsky and E. Nudler, "New insights into the mechanism of heat shock response activation," Cellular and Molecular Life Sciences, vol. 65, no. 6, pp. 855-861, 2008.

[97] R. Voellmy, "On mechanisms that control heat shock transcription factor activity in metazoan cells," Cell Stress and Chaperones, vol. 9, no. 2, pp. 122-133, 2004.

[98] M. Jäättelä, "Heat shock proteins as cellular lifeguards," Annals of Medicine, vol. 31, no. 4, pp. 261-271, 1999.

[99] S. Lindquist and E. A. Craig, "The heat-shock proteins," Annual Review of Genetics, vol. 22, pp. 631-677, 1988.

[100] C. Garrido, "Size matters: of the small HSP27 and its large oligomers," Cell Death and Differentiation, vol. 9, no. 5, pp. 483-485, 2002.

[101] M. Jäättelä, D. Wissing, K. Kokholm, T. Kallunki, and M. Egeblad, "Hsp7O exerts its anti-apoptotic function downstream of caspase-3-like proteases," EMBO Journal, vol. 17, no. 21, pp. 6124-6134, 1998.

[102] A. E. Kabakov and V. L. Gabai, "Heat-shock-induced accumulation of $70-\mathrm{kDa}$ stress protein (HSP70) can protect ATP-depleted tumor cells from necrosis," Experimental Cell Research, vol. 217, no. 1, pp. 15-21, 1995.

[103] P. Mehlen, X. Preville, P. Chareyron, J. Briolay, R. Klemenz, and A. P. Arrigo, "Constitutive expression of human hsp27, Drosophila hsp27, or human $\alpha \mathrm{B}$ - crystallin confers resistance to TNF- and oxidative stress-induced cytotoxicity in stably transfected murine L929 fibroblasts," Journal of Immunology, vol. 154, no. 1, pp. 363-374, 1995.

[104] M. J. Champagne, P. Dumas, S. N. Orlov, M. R. Bennett, P. Hamet, and J. Tremblay, "Protection against necrosis but not apoptosis by heat-stress proteins in vascular smooth muscle cells: evidence for distinct modes of cell death," Hypertension, vol. 33, no. 3, pp. 906-913, 1999.

[105] F. U. Hartl and M. Hayer-Hartl, "Molecular chaperones in the cytosol: from nascent chain to folded protein," Science, vol. 295, no. 5561, pp. 1852-1858, 2002.

[106] C. G. Concannon, A. M. Gorman, and A. Samali, "On the role of Hsp27 in regulating apoptosis," Apoptosis, vol. 8, no. 1, pp. 61-70, 2003.

[107] C. G. Concannon, S. Orrenius, and A. Samali, "Hsp27 inhibits cytochrome c-mediated caspase activation by sequestering both pro-caspase-3 and cytochrome c," Gene Expression, vol. 9, no. 4-5, pp. 195-201, 2001.

[108] P. Pandey, R. Farber, A. Nakazawa, et al., "Hsp27 functions as a negative regulator of cytochrome c-dependent activation of procaspase-3," Oncogene, vol. 19, no. 16, pp. 1975-1981, 2000.

[109] J.-M. Bruey, C. Ducasse, P. Bonniaud, et al., "Hsp27 negatively regulates cell death by interacting with cytochrome c," Nature Cell Biology, vol. 2, no. 9, pp. 645-652, 2000.

[110] A. Samali, J. D. Robertson, E. Peterson, et al., "Hsp27 protects mitochondria of thermotolerant cells against apoptotic stimuli," Cell Stress and Chaperones, vol. 6, no. 1, pp. 49-58, 2001.
[111] D. Chauhan, G. Li, T. Hideshima, et al., "Hsp27 inhibits release of mitochondrial protein Smac in multiple myeloma cells and confers dexamethasone resistance," Blood, vol. 102, no. 9, pp. 3379-3386, 2003.

[112] R. Steel, J. P. Doherty, K. Buzzard, N. Clemons, C. J. Hawkins, and R. L. Anderson, "Hsp72 inhibits apoptosis upstream of the mitochondria and not through interactions with Apaf-1," Journal of Biological Chemistry, vol. 279, no. 49, pp. 5149051499, 2004.

[113] A. Saleh, S. M. Srinivasula, L. Balkir, P. D. Robbins, and E. S. Alnemri, "Negative regulation of the Apaf-1 apoptosome by Hsp70," Nature Cell Biology, vol. 2, no. 8, pp. 476-483, 2000.

[114] H. M. Beere, B. B. Wolf, K. Cain, et al., "Heat-shock protein 70 inhibits apoptosis by preventing recruitment of procaspase-9 to the Apaf-1 apoptosome," Nature Cell Biology, vol. 2, no. 8, pp. 469-475, 2000.

[115] E. Yu. Komarova, E. A. Afanasyeva, M. M. Bulatova, M. E. Cheetham, B. A. Margulis, and I. V. Guzhova, "Downstream caspases are novel targets for the antiapoptotic activity of the molecular chaperone Hsp70," Cell Stress and Chaperones, vol. 9, no. 3, pp. 265-275, 2004.

[116] E. M. Creagh, R. J. Carmody, and T. G. Cotter, "Heat shock protein 70 inhibits caspase-dependent and -independent apoptosis in Jurkat T cells," Experimental Cell Research, vol. 257, no. 1, pp. 58-66, 2000.

[117] L. Ravagnan, S. Gurbuxani, S. A. Susin, et al., "Heat-shock protein 70 antagonizes apoptosis-inducing factor," Nature Cell Biology, vol. 3, no. 9, pp. 839-843, 2001.

[118] S. J. Charette and J. Landry, "The interaction of HSP27 with Daxx identifies a potential regulatory role of HSP27 in Fas-induced apoptosis," Annals of the New York Academy of Sciences, vol. 926, pp. 126-131, 2000.

[119] V. L. Gabai, J. A. Yaglom, V. Volloch, et al., "Hsp72-mediated suppression of c-Jun N-terminal kinase is implicated in development of tolerance to caspase-independent cell death," Molecular \& Cellular Biology, vol. 20, no. 18, pp. 6826-6836, 2000.

[120] D. D. Mosser, A. W. Caron, L. Bourget, C. Denis-Larose, and B. Massie, "Role of the human heat shock protein hsp70 in protection against stress-induced apoptosis," Molecular \& Cellular Biology, vol. 17, no. 9, pp. 5317-5327, 1997.

[121] J. Park and A. Y. C. Liu, "JNK phosphorylates the HSF1 transcriptional activation domain: role of JNK in the regulation of the heat shock response," Journal of Cellular Biochemistry, vol. 82, no. 2, pp. 326-338, 2001.

[122] H. Konishi, H. Matsuzaki, M. Tanaka, et al., "Activation of protein kinase B (Akt/RAC-protein kinase) by cellular stress and its association with heat shock protein Hsp27," FEBS Letters, vol. 410, no. 2-3, pp. 493-498, 1997.

[123] K. M. Mearow, M. E. Dodge, M. Rahimtula, and C. Yegappan, "Stress-mediated signaling in PC12 cells-the role of the small heat shock protein, Hsp27, and Akt in protecting cells from heat stress and nerve growth factor withdrawal," Journal of Neurochemistry, vol. 83, no. 2, pp. 452-462, 2002.

[124] M. J. Rane, Y. Pan, S. Singh, et al., "Heat shock protein 27 controls apoptosis by regulating Akt activation," Journal of Biological Chemistry, vol. 278, no. 30, pp. 27828-27835, 2003.

[125] X.-B. Qiu, Y.-M. Shao, S. Miao, and L. Wang, "The diversity of the DnaJ/Hsp40 family, the crucial partners for Hsp70 chaperones," Cellular \& Molecular Life Sciences, vol. 63, no. 22, pp. 2560-2570, 2006.

[126] S. Takayama, D. N. Bimston, S.-I. Matsuzawa, et al., "BAG1 modulates the chaperone activity of $\mathrm{Hsp} 70 / \mathrm{Hsc70}$," EMBO Journal, vol. 16, no. 16, pp. 4887-4896, 1997. 
[127] M. Schröder and R. J. Kaufman, "The mammalian unfolded protein response," Annual Review of Biochemistry, vol. 74, pp. 739-789, 2005.

[128] D. Ron and P. Walter, "Signal integration in the endoplasmic reticulum unfolded protein response," Nature Reviews Molecular Cell Biology, vol. 8, no. 7, pp. 519-529, 2007.

[129] S. Kondo, T. Murakami, K. Tatsumi, et al., "OASIS, a CREB/ATF-family member, modulates UPR signalling in astrocytes," Nature Cell Biology, vol. 7, no. 2, pp. 186-194, 2005.

[130] K. Zhang, X. Shen, J. Wu, et al., "Endoplasmic reticulum stress activates cleavage of CREBH to induce a systemic inflammatory response," Cell, vol. 124, no. 3, pp. 587-599, 2006.

[131] I. Nagamori, K. Yomogida, M. Ikawa, M. Okabe, N. Yabuta, and H. Nojima, "The testes-specific bZip type transcription factor Tisp40 plays a role in ER stress responses and chromatin packaging during spermiogenesis," Genes to Cells, vol. 11, no. 10, pp. 1161-1171, 2006.

[132] G. Liang, T. E. Audas, Y. Li, et al., "Luman/CREB3 induces transcription of the endoplasmic reticulum (ER) stress response protein herp through an ER stress response element," Molecular \& Cellular Biology, vol. 26, no. 21, pp. 79998010, 2006.

[133] J. S. Cox and P. Walter, "A novel mechanism for regulating activity of a transcription factor that controls the unfolded protein response," Cell, vol. 87, no. 3, pp. 391-404, 1996.

[134] K. Mori, T. Kawahara, H. Yoshida, H. Yanagi, and T. Yura, "Signalling from endoplasmic reticulum to nucleus: transcription factor with a basic-leucine zipper motif is required for the unfolded protein-response pathway," Genes to Cells, vol. 1, no. 9, pp. 803-817, 1996.

[135] H. Yoshida, T. Matsui, A. Yamamoto, T. Okada, and K. Mori, "XBP1 mRNA is induced by ATF6 and spliced by IRE1 in response to ER stress to produce a highly active transcription factor," Cell, vol. 107, no. 7, pp. 881-891, 2001.

[136] M. Calfon, H. Zeng, F. Urano, et al., "IRE1 couples endoplasmic reticulum load to secretory capacity by processing the XBP-1 mRNA," Nature, vol. 415, no. 6867, pp. 92-96, 2002.

[137] H. P. Harding, Y. Zhang, and D. Ron, "Protein translation and folding are coupled by an endoplasmic-reticulum-resident kinase," Nature, vol. 397, no. 6716, pp. 271-274, 1999.

[138] P. D. Lu, H. P. Harding, and D. Ron, "Translation reinitiation at alternative open reading frames regulates gene expression in an integrated stress response," Journal of Cell Biology, vol. 167, no. 1, pp. 27-33, 2004.

[139] S. B. Cullinan, D. Zhang, M. Hannink, E. Arvisais, R. J. Kaufman, and J. A. Diehl, "Nrf2 is a direct PERK substrate and effector of PERK-dependent cell survival," Molecular \& Cellular Biology, vol. 23, no. 20, pp. 7198-7209, 2003.

[140] S. B. Cullinan and J. A. Diehl, "PERK-dependent activation of Nrf2 contributes to redox homeostasis and cell survival following endoplasmic reticulum stress," Journal of Biological Chemistry, vol. 279, no. 19, pp. 20108-20117, 2004.

[141] K. Haze, H. Yoshida, H. Yanagi, T. Yura, and K. Mori, "Mammalian transcription factor ATF6 is synthesized as a transmembrane protein and activated by proteolysis in response to endoplasmic reticulum stress," Molecular Biology of the Cell, vol. 10, no. 11, pp. 3787-3799, 1999.

[142] J. Ye, R. B. Rawson, R. Komuro, et al., "ER stress induces cleavage of membrane-bound ATF6 by the same proteases that process SREBPs," Molecular Cell, vol. 6, no. 6, pp. 1355$1364,2000$.
[143] M. Tamatani, T. Matsuyama, A. Yamaguchi, et al., "ORP150 protects against hypoxia/ischemia-induced neuronal death," Nature Medicine, vol. 7, no. 3, pp. 317-323, 2001.

[144] O. Hori, M. Miyazaki, T. Tamatani, et al., "Deletion of SERP1/RAMP4, a component of the endoplasmic reticulum (ER) translocation sites, leads to ER stress," Molecular \& Cellular Biology, vol. 26, no. 11, pp. 4257-4267, 2006.

[145] T. Nakagawa, H. Zhu, N. Morishima, et al., "Caspase12 mediates endoplasmic-reticulum-specific apoptosis and cytotoxicity by amyloid- $\beta$," Nature, vol. 403 , no. 6765 , pp. 98-103, 2000.

[146] J. Hitomi, T. Katayama, Y. Eguchi, et al., "Involvement of caspase- 4 in endoplasmic reticulum stress-induced apoptosis and A $\beta$-induced cell death," Journal of Cell Biology, vol. 165, no. 3, pp. 347-356, 2004.

[147] R. V. Rao, S. Castro-Obregon, H. Frankowski, et al., "Coupling endoplasmic reticulum stress to the cell death program. An Apaf-1-independent intrinsic pathway," Journal of Biological Chemistry, vol. 277, no. 24, pp. 21836-21842, 2002.

[148] K. D. McCullough, J. L. Martindale, L.-O. Klotz, T.-Y. Aw, and N. J. Holbrook, "Gadd153 sensitizes cells to endoplasmic reticulum stress by down-regulating $\mathrm{Bc} 12$ and perturbing the cellular redox state," Molecular \& Cellular Biology, vol. 21, no. 4, pp. 1249-1259, 2001.

[149] H. Puthalakath, L. A. O’Reilly, P. Gunn, et al., "ER stress triggers apoptosis by activating $\mathrm{BH} 3$-only protein Bim," Cell, vol. 129, no. 7, pp. 1337-1349, 2007.

[150] F. Urano, X. Wang, A. Bertolotti, et al., "Coupling of stress in the ER to activation of JNK protein kinases by transmembrane protein kinase IRE1," Science, vol. 287, no. 5453, pp. 664-666, 2000.

[151] H. Nishitoh, A. Matsuzawa, K. Tobiume, et al., "ASK1 is essential for endoplasmic reticulum stress-induced neuronal cell death triggered by expanded polyglutamine repeats," Genes and Development, vol. 16, no. 11, pp. 1345-1355, 2002.

[152] M. Ni and A. S. Lee, "ER chaperones in mammalian development and human diseases," FEBS Letters, vol. 581, no. 19, pp. 3641-3651, 2007.

[153] A. M. Gorman, "Neuronal cell death in neurodegenerative diseases: recurring themes around protein handling," Journal of Cellular \& Molecular Medicine, vol. 12, no. 6, pp. 22632280, 2008.

[154] A. N. Mhaille, S. McQuaid, A. Windebank, et al., "Increased expression of endoplasmic reticulum stress-related signaling pathway molecules in multiple sclerosis lesions," Journal of Neuropathology \& Experimental Neurology, vol. 67, no. 3, pp. 200-211, 2008.

[155] C. Holohan, E. Szegezdi, T. Ritter, T. O'Brien, and A. Samali, "Cytokine-induced $\beta$-cell apoptosis is NOdependent, mitochondria-mediated and inhibited by BCL$\mathrm{X}_{L}$," Journal of Cellular \& Molecular Medicine, vol. 12, no. 2, pp. 591-606, 2008.

[156] R. P. C. Shiu, J. Pouyssegur, and I. Pastan, "Glucose depletion accounts for the induction of two transformation-sensitive membrane proteins in Rous sarcoma virus-transformed chick embryo fibroblasts," Proceedings of the National Academy of Sciences of the United States of America, vol. 74, no. 9, pp. 3840-3844, 1977.

[157] H. Yoshida, K. Haze, H. Yanagi, T. Yura, and K. Mori, "Identification of the cis-acting endoplasmic reticulum stress response element responsible for transcriptional induction of mammalian glucose-regulated proteins: involvement of basic 
leucine zipper transcription factors," Journal of Biological Chemistry, vol. 273, no. 50, pp. 33741-33749, 1998.

[158] S. Tanaka, T. Uehara, and Y. Nomura, "Up-regulation of protein-disulfide isomerase in response to hypoxia/brain ischemia and its protective effect against apoptotic cell death," Journal of Biological Chemistry, vol. 275, no. 14, pp. 10388-10393, 2000.

[159] Y. Kitao, K. Ozawa, M. Miyazaki, et al., "Expression of the endoplasmic reticulum molecular chaperone (ORP150) rescues hippocampal neurons from glutamate toxicity," Journal of Clinical Investigation, vol. 108, no. 10, pp. 1439-1450, 2001.

[160] T. Uehara, T. Nakamura, D. Yao, et al., "S-nitrosylated protein-disulphide isomerase links protein misfolding to neurodegeneration," Nature, vol. 441, no. 7092, pp. 513-517, 2006.

[161] Y. Kitao, Y. Imai, K. Ozawa, et al., "Pael receptor induces death of dopaminergic neurons in the substantia nigra via endoplasmic reticulum stress and dopamine toxicity, which is enhanced under condition of parkin inactivation," Human Molecular Genetics, vol. 16, no. 1, pp. 50-60, 2007.

[162] T. Hoshino, T. Nakaya, W. Araki, K. Suzuki, T. Suzuki, and T. Mizushima, "Endoplasmic reticulum chaperones inhibit the production of amyloid- $\beta$ peptides," Biochemical Journal, vol. 402, no. 3, pp. 581-589, 2007.

[163] R. E. Feaver, N. E. Hastings, A. Pryor, and B. R. Blackman, "GRP78 upregulation by atheroprone shear stress via p38-, $\alpha 2 \beta 1$-dependent mechanism in endothelial cells," Arteriosclerosis, Thrombosis, and Vascular Biology, vol. 28, no. 8, pp. 1534-1541, 2008.

[164] C. Zhang, Y. Cai, M. T. Adachi, et al., "Homocysteine induces programmed cell death in human vascular endothelial cells through activation of the unfolded protein response," Journal of Biological Chemistry, vol. 276, no. 38, pp. 35867-35874, 2001.

[165] G. H. Werstuck, S. R. Lentz, S. Dayal, et al., "Homocysteineinduced endoplasmic reticulum stress causes dysregulation of the cholesterol and triglyceride biosynthetic pathways," Journal of Clinical Investigation, vol. 107, no. 10, pp. 12631273, 2001.

[166] L. M. Watson, A. K. C. Chan, L. R. Berry, et al., "Overexpression of the $78-\mathrm{kDa}$ glucose-regulated protein/immunoglobulin-binding protein (GRP78/BiP) inhibits tissue factor procoagulant activity," Journal of Biological Chemistry, vol. 278, no. 19, pp. 17438-17447, 2003.

[167] S. Luo, C. Mao, B. Lee, and A. S. Lee, "GRP78/BiP is required for cell proliferation and protecting the inner cell mass from apoptosis during early mouse embryonic development," Molecular \& Cellular Biology, vol. 26, no. 15, pp. 5688-5697, 2006.

[168] N. Mesaeli, K. Nakamura, E. Zvaritch, et al., "Calreticulin is essential for cardiac development," Journal of Cell Biology, vol. 144, no. 5, pp. 857-868, 1999.

[169] Y. Kitao, K. Hashimoto, T. Matsuyama, et al., "ORP150/HSP12A regulates purkinje cell survival: a role for endoplasmic reticulum stress in cerebellar development," Journal of Neuroscience, vol. 24, no. 6, pp. 1486-1496, 2004.

[170] K. Kubota, Y. Niinuma, M. Kaneko, et al., "Suppressive effects of 4-phenylbutyrate on the aggregation of Pael receptors and endoplasmic reticulum stress," Journal of Neurochemistry, vol. 97, no. 5, pp. 1259-1268, 2006.

[171] S.-E. Choi, Y.-J. Lee, H.-J. Jang, et al., "A chemical chaperone 4-PBA ameliorates palmitate-induced inhibition of glucose-stimulated insulin secretion (GSIS)," Archives of Biochemistry and Biophysics, vol. 475, no. 2, pp. 109-114, 2008.

[172] T. Kudo, S. Kanemoto, H. Hara, et al., "A molecular chaperone inducer protects neurons from ER stress," Cell Death and Differentiation, vol. 15, no. 2, pp. 364-375, 2008.

[173] K. Takano, Y. Tabata, Y. Kitao, et al., "Methoxyflavones protect cells against endoplasmic reticulum stress and neurotoxin," American Journal of Physiology, vol. 292, no. 1, pp. C353-C361, 2007.

[174] W. P. Roos and B. Kaina, "DNA damage-induced cell death by apoptosis," Trends in Molecular Medicine, vol. 12, no. 9, pp. 440-450, 2006.

[175] M. Christmann, M. T. Tomicic, W. P. Roos, and B. Kaina, "Mechanisms of human DNA repair: an update," Toxicology, vol. 193, no. 1-2, pp. 3-34, 2003.

[176] D. J. Richard, E. Bolderson, and K. K. Khanna, "Multiple human single-stranded DNA binding proteins function in genome maintenance: structural, biochemical and functional analysis," Critical Reviews in Biochemistry and Molecular Biology, vol. 44, no. 2-3, pp. 98-116, 2009.

[177] L. Staresincic, A. F. Fagbemi, J. H. Enzlin, et al., "Coordination of dual incision and repair synthesis in human nucleotide excision repair," EMBO Journal, vol. 28, no. 8, pp. 1111-1120, 2009.

[178] J. W. Harper and S. J. Elledge, "The DNA damage response: ten years after," Molecular Cell, vol. 28, no. 5, pp. 739-745, 2007.

[179] K. H. Vousden and D. P. Lane, "p53 in health and disease," Nature Reviews Molecular Cell Biology, vol. 8, no. 4, pp. 275283, 2007.

[180] A. V. Vaseva and U. M. Moll, "The mitochondrial p53 pathway," Biochimica et Biophysica Acta, vol. 1787, no. 5, pp. 414-420, 2009.

[181] S. P. Jackson, "Sensing and repairing DNA double-strand breaks," Carcinogenesis, vol. 23, no. 5, pp. 687-696, 2002.

[182] K. Valerie and L. F. Povirk, "Regulation and mechanisms of mammalian double-strand break repair," Oncogene, vol. 22, no. 37, pp. 5792-5812, 2003.

[183] D. E. Barnes and T. Lindahl, "Repair and genetic consequences of endogenous DNA base damage in mammalian cells," Annual Review of Genetics, vol. 38, pp. 445-476, 2004.

[184] L. Stojic, R. Brun, and J. Jiricny, "Mismatch repair and DNA damage signalling," DNA Repair, vol. 3, no. 8-9, pp. 10911101, 2004.

[185] J. H. J. Hoeijmakers, "Genome maintenance mechanisms for preventing cancer," Nature, vol. 411, no. 6835, pp. 366-374, 2001.

[186] D. Trachootham, W. Lu, M. A. Ogasawara, N. R.-D. Valle, and P. Huang, "Redox regulation of cell survival," Antioxidants \& Redox Signaling, vol. 10, no. 8, pp. 1343-1374, 2008.

[187] B. Brune, "The intimate relation between nitric oxide and superoxide in apoptosis and cell survival," Antioxidants \& Redox Signaling, vol. 7, no. 3-4, pp. 497-507, 2005.

[188] K. Niizuma, H. Endo, and P. H. Chan, "Oxidative stress and mitochondrial dysfunction as determinants of ischemic neuronal death and survival," Journal of Neurochemistry, vol. 109, supplement 1, pp. 133-138, 2009.

[189] S. Orrenius, V. Gogvadze, and B. Zhivotovsky, "Mitochondrial oxidative stress: implications for cell death," Annual Review of Pharmacology \& Toxicology, vol. 47, pp. 143-183, 2007. 
[190] M. Genestra, "Oxyl radicals, redox-sensitive signalling cascades and antioxidants," Cellular Signalling, vol. 19, no. 9, pp. 1807-1819, 2007.

[191] P. Zaccagnino, M. Saltarella, S. D’Oria, A. Corcelli, M. S. Saponetti, and M. Lorusso, "N-arachidonylglycine causes ROS production and cytochrome $\mathrm{c}$ release in liver mitochondria," Free Radical Biology \& Medicine, vol. 47, no. 5, pp. 585592, 2009.

[192] A. Sapone, A. Affatato, D. Canistro, et al., "Induction and suppression of cytochrome P450 isoenzymes and generation of oxygen radicals by procymidone in liver, kidney and lung of CD1 mice," Mutation Research, vol. 527, no. 1-2, pp. 67-80, 2003.

[193] X. Gong, R. Gutala, and A. K. Jaiswal, "Quinone oxidoreductases and vitamin K metabolism," Vitamins and Hormones, vol. 78, pp. 85-101, 2008.

[194] J. D. Robertson, J. Chandra, V. Gogvadze, and S. Orrenius, "Biological reactive intermediates and mechanisms of cell death," Advances in Experimental Medicine and Biology, vol. 500, pp. 1-10, 2001.

[195] A. M. Gorman, B. Heavey, E. Creagh, T. G. Cotter, and A. Samali, "Antioxidant-mediated inhibition of the heat shock response leads to apoptosis," FEBS Letters, vol. 445, no. 1, pp. 98-102, 1999.

[196] A. M. Gorman, E. Szegezdi, D. J. Quigney, and A. Samali, "Hsp27 inhibits 6-hydroxydopamine-induced cytochrome c release and apoptosis in PC12 cells," Biochemical \& Biophysical Research Communications, vol. 327, no. 3, pp. 801-810, 2005.

[197] W. R. Swindell, M. Huebner, and A. P. Weber, "Transcriptional profiling of arabidopsis heat shock proteins and transcription factors reveals extensive overlap between heat and non-heat stress response pathways," BMC Genomics, vol. 8, article 125, 2007.

[198] S. B. Cullinan and J. A. Diehl, "Coordination of ER and oxidative stress signaling: the PERK/Nrf2 signaling pathway," International Journal of Biochemistry \& Cell Biology, vol. 38, no. 3, pp. 317-332, 2006.

[199] S. B. Cullinan and J. A. Diehl, "PERK-dependent activation of Nrf2 contributes to redox homeostasis and cell survival following endoplasmic reticulum stress," Journal of Biological Chemistry, vol. 279, no. 19, pp. 20108-20117, 2004.

[200] Y. Chen, M. B. Azad, and S. B. Gibson, "Superoxide is the major reactive oxygen species regulating autophagy," Cell Death and Differentiation, vol. 16, no. 7, pp. 1040-1052, 2009.

[201] A. Gorman, A. McGowan, and T. G. Cotter, "Role of peroxide and superoxide anion during tumour cell apoptosis," FEBS Letters, vol. 404, no. 1, pp. 27-33, 1997.

[202] M. Meyer, R. Schreck, and P. A. Baeuerle, " $\mathrm{H}_{2} \mathrm{O}_{2}$ and antioxidants have opposite effects on activation of NF-kappa $\mathrm{B}$ and AP-1 in intact cells: AP-1 as secondary antioxidantresponsive factor," EMBO Journal, vol. 12, no. 5, pp. 20052015, 1993.

[203] T. L. Denning, H. Takaishi, S. E. Crowe, I. Boldogh, A. Jevnikar, and P. B. Ernst, "Oxidative stress induces the expression of Fas and Fas ligand and apoptosis in murine intestinal epithelial cells," Free Radical Biology \& Medicine, vol. 33, no. 12, pp. 1641-1650, 2002.

[204] H. Hug, S. Strand, A. Grambihler, et al., "Reactive oxygen intermediates are involved in the induction of CD95 ligand mRNA expression by cytostatic drugs in hepatoma cells," Journal of Biological Chemistry, vol. 272, no. 45, pp. 2819128193, 1997.
[205] K. Dobashi, K. Pahan, A. Chahal, and I. Singh, "Modulation of endogenous antioxidant enzymes by nitric oxide in rat C6 glial cells," Journal of Neurochemistry, vol. 68, no. 5, pp. 18961903, 1997.

[206] M. Asahi, J. Fujii, K. Suzuki, et al., "Inactivation of glutathione peroxidase by nitric oxide. Implication for cytotoxicity," Journal of Biological Chemistry, vol. 270, no. 36, pp. 21035-21039, 1995.

[207] L. Bosca and S. Hortelano, "Mechanisms of nitric oxidedependent apoptosis: involvement of mitochondrial mediators," Cellular Signalling, vol. 11, no. 4, pp. 239-244, 1999.

[208] Z. X. Chen and S. Pervaiz, "BCL-2: pro-or anti-oxidant?" Frontiers in Bioscience, vol. 1, pp. 263-268, 2009.

[209] N. Mirkovic, D. W. Voehringer, M. D. Story, D. J. McConkey, T. J. McDonnell, and R. E. Meyn, "Resistance to radiationinduced apoptosis in bcl-2-expressing cells is reversed by depleting cellular thiols," Oncogene, vol. 15, no. 12, pp. 14611470, 1997.

[210] N. M. Robertson, J. Zangrilli, T. Fernandes-Alnemri, P. D. Friesen, G. Litwack, and E. S. Alnemri, "Baculovirus P35 inhibits the glucocorticoid-mediated pathway of cell death," Cancer Research, vol. 57, no. 1, pp. 43-47, 1997.

[211] N. K. Sah, T. K. Taneja, N. Pathak, R. Begum, M. Athar, and S. E. Hasnain, "The baculovirus antiapoptotic p35 gene also functions via an oxidant-dependent pathway," Proceedings of the National Academy of Sciences of the United States of America, vol. 96, no. 9, pp. 4838-4843, 1999.

[212] E. S. Alnemri, D. J. Livingston, D. W. Nicholson, et al., "Human ICE/CED-3 protease nomenclature," Cell, vol. 87, no. 2, p. 171, 1996.

[213] J. Chandra, A. Samali, and S. Orrenius, "Triggering and modulation of apoptosis by oxidative stress," Free Radical Biology \& Medicine, vol. 29, no. 3-4, pp. 323-333, 2000.

[214] G. Melino, F. Bernassola, R. A. Knight, M. T. Corasaniti, G. Nistico, and A. Finazzi-Agro, "S-nitrosylation regulates apoptosis," Nature, vol. 388, no. 6641, pp. 432-433, 1997.

[215] M. Leist, B. Single, H. Naumann, et al., "Inhibition of mitochondrial ATP generation by nitric oxide switches apoptosis to necrosis," Experimental Cell Research, vol. 249, no. 2, pp. 396-403, 1999.

[216] Y. Tsujimoto, S. Shimizu, Y. Eguchi, W. Kamiike, and H. Matsuda, "BCL-2 and Bcl-xL block apoptosis as well as necrosis: possible involvement of common mediators in apoptotic and necrotic signal transduction pathways," Leukemia, vol. 11, supplement 3, pp. 380-382, 1997.

[217] M. C. Maiuri, E. Zalckvar, A. Kimchi, and G. Kroemer, "Self-eating and self-killing: crosstalk between autophagy and apoptosis," Nature Reviews Molecular Cell Biology, vol. 8, no. 9, pp. 741-752, 2007.

[218] B. Kalmar and L. Greensmith, "Activation of the heat shock response in a primary cellular model of motoneuron neurodegeneration-evidence for neuroprotective and neurotoxic effects," Cellular \& Molecular Biology Letters, vol. 14, no. 2, pp. 319-335, 2009.

[219] J. H. Lin, H. Li, D. Yasumura, et al., "IRE1 signaling affects cell fate during the unfolded protein response," Science, vol. 318, no. 5852, pp. 944-949, 2007.

[220] A. Jorns, A. Gunther, H.-J. Hedrich, D. Wedekind, M. Tiedge, and S. Lenzen, "Immune cell infiltration, cytokine expression, and $\beta$-cell apoptosis during the development of type 1 diabetes in the spontaneously diabetic LEW.1AR1/Ztm-iddm rat," Diabetes, vol. 54, no. 7, pp. 2041-2052, 2005. 
[221] D. L. Eizirik and T. Mandrup-Poulsen, "A choice of deaththe signal-transduction of immune-mediated beta-cell apoptosis," Diabetologia, vol. 44, no. 12, pp. 2115-2133, 2001.

[222] K. L. A. Souza, E. Gurgul-Convey, M. Elsner, and S. Lenzen, "Interaction between pro-inflammatory and antiinflammatory cytokines in insulin-producing cells," Journal of Endocrinology, vol. 197, no. 1, pp. 139-150, 2008.

[223] P. Pirot, D. L. Eizirik, and A. K. Cardozo, "Interferon- $\gamma$ potentiates endoplasmic reticulum stress-induced death by reducing pancreatic beta cell defence mechanisms," Diabetologia, vol. 49, no. 6, pp. 1229-1236, 2006.

[224] S. Lortz, E. Gurgul-Convey, S. Lenzen, and M. Tiedge, "Importance of mitochondrial superoxide dismutase expression in insulin-producing cells for the toxicity of reactive oxygen species and proinflammatory cytokines," Diabetologia, vol. 48 , no. 8, pp. 1541-1548, 2005.

[225] A. K. Azevedo-Martins, S. Lortz, S. Lenzen, R. Curi, D. L. Eizirik, and M. Tiedge, "Improvement of the mitochondrial antioxidant defense status prevents cytokine-induced nuclear factor- $\kappa$ B activation in insulin-producing cells," Diabetes, vol. 52, no. 1, pp. 93-101, 2003.

[226] S. Lenzen, J. Drinkgern, and M. Tiedge, "Low antioxidant enzyme gene expression in pancreatic islets compared with various other mouse tissues," Free Radical Biology \& Medicine, vol. 20, no. 3, pp. 463-466, 1996.

[227] M. Tiedge, S. Lortz, J. Drinkgern, and S. Lenzen, "Relation between antioxidant enzyme gene expression and antioxidative defense status of insulin-producing cells," Diabetes, vol. 46, no. 11, pp. 1733-1742, 1997.

[228] E. Gurgul, S. Lortz, M. Tiedge, A. Jorns, and S. Lenzen, "Mitochondrial catalase overexpression protects insulinproducing cells against toxicity of reactive oxygen species and proinflammatory cytokines," Diabetes, vol. 53, no. 9, pp. 2271-2280, 2004.

[229] D. L. Eizirik, A. K. Cardozo, and M. Cnop, "The role for endoplasmic reticulum stress in diabetes mellitus," Endocrine Reviews, vol. 29, no. 1, pp. 42-61, 2008.

[230] J. L. Evans, I. D. Goldfine, B. A. Maddux, and G. M. Grodsky, "Are oxidative stress-activated signaling pathways mediators of insulin resistance and $\beta$-cell dysfunction?" Diabetes, vol. 52, no. 1, pp. 1-8, 2003.

[231] E. Diakogiannaki, S. Dhayal, C. E. Childs, P. C. Calder, H. J. Welters, and N. G. Morgan, "Mechanisms involved in the cytotoxic and cytoprotective actions of saturated versus monounsaturated long-chain fatty acids in pancreatic $\beta$ cells," Journal of Endocrinology, vol. 194, no. 2, pp. 283-291, 2007.

[232] R. Robertson, H. Zhou, T. Zhang, and J. S. Harmon, "Chronic oxidative stress as a mechanism for glucose toxicity of the beta cell in type 2 diabetes," Cell Biochemistry \& Biophysics, vol. 48, no. 2-3, pp. 139-146, 2007.

[233] M. Cnop, N. Welsh, J.-C. Jonas, A. Jorns, S. Lenzen, and D. L. Eizirik, "Mechanisms of pancreatic $\beta$-cell death in type 1 and type 2 diabetes: many differences, few similarities," Diabetes, vol. 54, supplement 2, pp. S97-S107, 2005.

[234] A. Jorns, K. J. Rath, O. Bock, and S. Lenzen, "Beta cell death in hyperglycaemic Psammomys obesus is not cytokinemediated," Diabetologia, vol. 49, no. 11, pp. 2704-2712, 2006.

[235] I. Kharroubi, L. Ladriere, A. K. Cardozo, Z. Dogusan, M. Cnop, and D. L. Eizirik, "Free fatty acids and cytokines induce pancreatic $\beta$-cell apoptosis by different mechanisms: role of nuclear factor- $\kappa \mathrm{B}$ and endoplasmic reticulum stress," Endocrinology, vol. 145, no. 11, pp. 5087-5096, 2004.
[236] F. M. Ashcroft, "K $\mathrm{K}_{\mathrm{ATP}}$ channels and insulin secretion: a key role in health and disease," Biochemical Society Transactions, vol. 34, part 2, pp. 243-246, 2006.

[237] M. C. Saleh, M. B. Wheeler, and C. B. Chan, "Uncoupling protein-2: evidence for its function as a metabolic regulator," Diabetologia, vol. 45, no. 2, pp. 174-187, 2002.

[238] J. H. Moffitt, B. A. Fielding, R. Evershed, R. Berstan, J. M. Currie, and A. Clark, "Adverse physicochemical properties of tripalmitin in beta cells lead to morphological changes and lipotoxicity in vitro," Diabetologia, vol. 48, no. 9, pp. 18191829, 2005.

[239] M. Delepine, M. Nicolino, T. Barrett, M. Golamaully, G. M. Lathrop, and C. Julier, "EIF2AK3, encoding translation initiation factor 2- $\alpha$ kinase 3 , is mutated in patients with Wolcott-Rallison syndrome," Nature Genetics, vol. 25, no. 4, pp. 406-409, 2000.

[240] H. P. Harding, H. Zeng, Y. Zhang, et al., "Diabetes mellitus and exocrine pancreatic dysfunction in perk-/- mice reveals a role for translational control in secretory cell survival," Molecular Cell, vol. 7, no. 6, pp. 1153-1163, 2001.

[241] J. Wang, T. Takeuchi, S. Tanaka, et al., "A mutation in the insulin 2 gene induces diabetes with severe pancreatic $\beta$ cell dysfunction in the Mody mouse," Journal of Clinical Investigation, vol. 103, no. 1, pp. 27-37, 1999.

[242] S. Oyadomari, A. Koizumi, K. Takeda, et al., "Targeted disruption of the Chop gene delays endoplasmic reticulum stress-mediated diabetes," Journal of Clinical Investigation, vol. 109, no. 4, pp. 525-532, 2002.

[243] W. C. Ladiges, S. E. Knoblaugh, J. F. Morton, et al., "Pancreatic $\beta$-cell failure and diabetes in mice with a deletion mutation of the endoplasmic reticulum molecular chaperone gene P58IPK," Diabetes, vol. 54, no. 4, pp. 1074-1081, 2005.

[244] P. Kovacs, X. Yang, P. A. Permana, C. Bogardus, and L. J. Baier, "Polymorphisms in the oxygen-regulated protein 150 gene (ORP150) are associated with insulin resistance in Pima Indians," Diabetes, vol. 51, no. 5, pp. 1618-1621, 2002.

[245] K. Ozawa, M. Miyazaki, M. Matsuhisa, et al., "The endoplasmic reticuluin chaperone improves insulin resistance in type 2 diabetes," Diabetes, vol. 54, no. 3, pp. 657-663, 2005.

[246] U. Ozcan, E. Yilmaz, L. Ozcan, et al., "Chemical chaperones reduce ER stress and restore glucose homeostasis in a mouse model of type 2 diabetes," Science, vol. 313, no. 5790, pp. 1137-1140, 2006.

[247] S. Gandhi and N. W. Wood, "Molecular pathogenesis of Parkinson's disease," Human Molecular Genetics, vol. 14, no. 18, pp. 2749-2755, 2005.

[248] S. Przedborski, "Pathogenesis of nigral cell death in Parkinson's disease," Parkinsonism and Related Disorders, vol. 11, supplement 1, pp. S3-S7, 2005.

[249] D. Sulzer, "Multiple hit hypotheses for dopamine neuron loss in Parkinson's disease," Trends in Neurosciences, vol. 30, no. 5, pp. 244-250, 2007.

[250] K. Steece-Collier, E. Maries, and J. H. Kordower, "Etiology of Parkinson's disease: genetics and environment revisited," Proceedings of the National Academy of Sciences of the United States of America, vol. 99, no. 22, pp. 13972-13974, 2002.

[251] J. M. Hatcher, K. D. Pennell, and G. W. Miller, "Parkinson's disease and pesticides: a toxicological perspective," Trends in Pharmacological Sciences, vol. 29, no. 6, pp. 322-329, 2008.

[252] H. Mochizuki, "Gene therapy for Parkinson's disease," Expert Review of Neurotherapeutics, vol. 7, no. 8, pp. 957-960, 2007.

[253] M. J. Farrer, "Genetics of Parkinson's disease: paradigm shifts and future prospects," Nature Reviews Genetics, vol. 7, no. 4, pp. 306-318, 2006. 
[254] M. W. Dodson and M. Guo, "Pink1, Parkin, DJ-1 and mitochondrial dysfunction in Parkinson's disease," Current Opinion in Neurobiology, vol. 17, no. 3, pp. 331-337, 2007.

[255] R. Banerjee, A. A. Starkov, M. F. Beal, and B. Thomas, "Mitochondrial dysfunction in the limelight of Parkinson's disease pathogenesis," Biochimica et Biophysica Acta, vol. 1792, no. 7, pp. 651-663, 2009.

[256] J. L. St Martin, J. Klucken, T. F. Outeiro, et al., "Dopaminergic neuron loss and up-regulation of chaperone protein mRNA induced by targeted over-expression of alpha-synuclein in mouse substantia nigra," Journal of Neurochemistry, vol. 100, no. 6, pp. 1449-1457, 2007.

[257] J. Klucken, Y. Shin, E. Masliah, B. T. Hyman, and P. J. McLean, "Hsp70 reduces $\alpha$-synuclein aggregation and toxicity," Journal of Biological Chemistry, vol. 279, no. 24, pp. 25497-25502, 2004.

[258] P. F. Durrenberger, M. D. Filiou, L. B. Moran, et al., "DnaJB6 is present in the core of Lewy bodies and is highly upregulated in Parkinsonian astrocytes," Journal of Neuroscience Research, vol. 87, no. 1, pp. 238-245, 2009.

[259] J. Fargnoli, T. Kunisada, A. J. Fornace Jr., E. L. Schneider, and N. J. Holbrook, "Decreased expression of heat shock protein 70 mRNA and protein after heat treatment in cells of aged rats," Proceedings of the National Academy of Sciences of the United States of America, vol. 87, no. 2, pp. 846-850, 1990.

[260] J. J. M. Hoozemans, E. S. van Haastert, P. Eikelenboom, R. A. I. de Vos, J. M. Rozemuller, and W. Scheper, "Activation of the unfolded protein response in Parkinson's disease," Biochemical \& Biophysical Research Communications, vol. 354, no. 3, pp. 707-711, 2007.

[261] W. A. Holtz and K. L. O’Malley, “Parkinsonian mimetics induce aspects of unfolded protein response in death of dopaminergic neurons," Journal of Biological Chemistry, vol. 278, no. 21, pp. 19367-19377, 2003.

[262] E. J. Ryu, H. P. Harding, J. M. Angelastro, O. V. Vitolo, D. Ron, and L. A. Greene, "Endoplasmic reticulum stress and the unfolded protein response in cellular models of Parkinson's disease," Journal of Neuroscience, vol. 22, no. 24, pp. 10690 10698, 2002.

[263] R. M. Silva, V. Ries, T. F. Oo, et al., "CHOP/GADD153 is a mediator of apoptotic death in substantia nigra dopamine neurons in an in vivo neurotoxin model of parkinsonism," Journal of Neurochemistry, vol. 95, no. 4, pp. 974-986, 2005.

[264] S. A. Fisher, B. L. Langille, and D. Srivastava, "Apoptosis during cardiovascular development," Circulation Research, vol. 87, no. 10, pp. 856-864, 2000.

[265] T. N. James, "Normal and abnormal consequences of apoptosis in the human heart: from postnatal morphogenesis to paroxysmal arrhythmias," Circulation, vol. 90, no. 1, pp. 556573, 1994.

[266] C. Gill, R. Mestril, and A. Samali, "Losing heart: the role of apoptosis in heart disease-a novel therapeutic target?" FASEB Journal, vol. 16, no. 2, pp. 135-146, 2002.

[267] A. B. Gustafsson and R. A. Gottlieb, "Mechanisms of apoptosis in the heart," Journal of Clinical Immunology, vol. 23 , no. 6, pp. 447-459, 2003.

[268] H. Fliss and D. Gattinger, "Apoptosis in ischemic and reperfused rat myocardium," Circulation Research, vol. 79, no. 5, pp. 949-956, 1996.

[269] R. A. Gottlieb, K. O. Burleson, R. A. Kloner, B. M. Babior, and R. L. Engler, "Reperfusion injury induces apoptosis in rabbit cardiomyocytes," Journal of Clinical Investigation, vol. 94, no. 4, pp. 1621-1628, 1994.
[270] J. Misao, Y. Hayakawa, M. Ohno, S. Kato, T. Fujiwara, and H. Fujiwara, "Expression of bcl-2 protein, an inhibitor of apoptosis, and Bax, an accelerator of apoptosis, in ventricular myocytes of human hearts with myocardial infarction," Circulation, vol. 94, no. 7, pp. 1506-1512, 1996.

[271] J. Narula, N. Haider, R. Virmani, et al., "Apoptosis in myocytes in end-stage heart failure," New England Journal of Medicine, vol. 335, no. 16, pp. 1182-1189, 1996.

[272] G. Olivetti, R. Abbi, F. Quaini, et al., "Apoptosis in the failing human heart," New England Journal of Medicine, vol. 336, no. 16, pp. 1131-1141, 1997.

[273] G. Olivetti, F. Quaini, R. Sala, et al., "Acute myocardial infarction in humans is associated with activation of programmed myocyte cell death in the surviving portion of the heart," Journal of Molecular \& Cellular Cardiology, vol. 28, no. 9, pp. 2005-2016, 1996.

[274] A. Saraste, K. Pulkki, M. Kallajoki, K. Henriksen, M. Parvinen, and L.-M. Voipio-Pulkki, "Apoptosis in human acute myocardial infarction," Circulation, vol. 95, no. 2, pp. 320-323, 1997.

[275] S. A. Cook, P. H. Sugden, and A. Clerk, "Regulation of bcl2 family proteins during development and in response to oxidative stress in cardiac myocytes association with changes in mitochondrial membrane potential," Circulation Research, vol. 85, no. 10, pp. 940-949, 1999.

[276] R. von Harsdorf, P.-F. Li, and R. Dietz, "Signaling pathways in reactive oxygen species-induced cardiomyocyte apoptosis," Circulation, vol. 99, no. 22, pp. 2934-2941, 1999.

[277] M. Neuss, R. Monticone, M. S. Lundberg, A. T. Chesley, E. Fleck, and M. T. Crow, "The apoptotic regulatory protein ARC (apoptosis repressor with caspase recruitment domain) prevents oxidant stress-mediated cell death by preserving mitochondrial function," Journal of Biological Chemistry, vol. 276, no. 36, pp. 33915-33922, 2001.

[278] C. Fleury, B. Mignotte, and J.-L. Vayssiere, "Mitochondrial reactive oxygen species in cell death signaling," Biochimie, vol. 84, no. 2-3, pp. 131-141, 2002.

[279] J. McMurray, J. McLay, M. Chopra, A. Bridges, and J. J. F. Belch, "Evidence for enhanced free radical activity in chronic congestive heart failure secondary to coronary artery disease," American Journal of Cardiology, vol. 65, no. 18, pp. 1261-1262, 1990.

[280] N. Singh and S. Aggarwal, "The effect of active oxygen generated by xanthine/xanthine oxidase on genes and signal transduction in mouse epidermal JB6 cells," International Journal of Cancer, vol. 62, no. 1, pp. 107-114, 1995.

[281] J. L. Zweier, J. T. Flaherty, and M. L. Weisfeldt, "Direct measurement of free radical generation following reperfusion of ischemic myocardium," Proceedings of the National Academy of Sciences of the United States of America, vol. 84, no. 5, pp. 1404-1407, 1987.

[282] S. E. Logue, A. B. Gustafsson, A. Samali, and R. A. Gottlieb, "Ischemia/reperfusion injury at the intersection with cell death," Journal of Molecular \& Cellular Cardiology, vol. 38, no. 1, pp. 21-33, 2005.

[283] K. Suzuki, Y. Sawa, Y. Kaneda, H. Ichikawa, R. Shirakura, and H. Matsuda, "In vivo gene transfection with heat shock protein 70 enhances myocardial tolerance to ischemiareperfusion injury in rat," Journal of Clinical Investigation, vol. 99, no. 7, pp. 1645-1650, 1997.

[284] A. N. Aleshin, Y. Sawa, S. Kitagawa-Sakakida, et al., “150-kDa oxygen-regulated protein attenuates myocardial ischemiareperfusion injury in rat heart," Journal of Molecular \& Cellular Cardiology, vol. 38, no. 3, pp. 517-525, 2005. 
[285] C.-Y. Li, J.-S. Lee, Y.-G. Ko, J.-I. Kim, and J.-S. Seo, "Heat shock protein 70 inhibits apoptosis downstream of cytochrome c release and upstream of caspase-3 activation," Journal of Biological Chemistry, vol. 275, no. 33, pp. 2566525671, 2000.

[286] M. A. H. Talukder, A. Kalyanasundaram, X. Zhao, et al., "Expression of SERCA isoform with faster $\mathrm{Ca}^{2+}$ transport properties improves postischemic cardiac function and $\mathrm{Ca}^{2+}$ handling and decreases myocardial infarction," American Journal of Physiology, vol. 293, no. 4, pp. H2418-H2428, 2007.

[287] S. W. Lowe and A. W. Lin, "Apoptosis in cancer," Carcinogenesis, vol. 21, no. 3, pp. 485-495, 2000.

[288] D. Hanahan and R. A. Weinberg, "The hallmarks of cancer," Cell, vol. 100, no. 1, pp. 57-70, 2000.

[289] S. W. Lowe, E. Cepero, and G. Evan, "Intrinsic tumour suppression," Nature, vol. 432, no. 7015, pp. 307-315, 2004.

[290] R. W. Johnstone, A. A. Ruefli, and S. W. Lowe, "Apoptosis: a link between cancer genetics and chemotherapy," Cell, vol. 108, no. 2, pp. 153-164, 2002.

[291] S. Fulda and K.-M. Debatin, "Targeting apoptosis pathways in cancer therapy," Current Cancer Drug Targets, vol. 4, no. 7, pp. 569-576, 2004.

[292] G. Makin and C. Dive, "Apoptosis and cancer chemotherapy," Trends in Cell Biology, vol. 11, no. 11, pp. S22-S26, 2001.

[293] C. Friesen, S. Fulda, and K.-M. Debatin, "Deficient activation of the CD95 (APO-1/Fas) system in drug-resistant cells," Leukemia, vol. 11, no. 11, pp. 1833-1841, 1997.

[294] S. Fulda, M. Los, C. Friesen, and K.-M. Debatin, "Chemosensitivity of solid tumor cells in vitro is related to activation of the CD95 system," International Journal of Cancer, vol. 76, no. 1, pp. 105-114, 1998.

[295] T. Maeda, Y. Yamada, R. Moriuchi, et al., "Fas gene mutation in the progression of adult T cell leukemia," Journal of Experimental Medicine, vol. 189, no. 7, pp. 1063-1071, 1999.

[296] T. H. Landowski, N. Qu, I. Buyuksal, J. S. Painter, and W. S. Dalton, "Mutations in the Fas antigen in patients with multiple myeloma," Blood, vol. 90, no. 11, pp. 4266-4270, 1997.

[297] K. Gronbaek, P. T. Straten, E. Ralfkiaer, et al., "Somatic fas mutations in non-Hodgkin's lymphoma: association with extranodal disease and autoimmunity," Blood, vol. 92, no. 9, pp. 3018-3024, 1998.

[298] S. H. Lee, M. S. Shin, W. S. Park, et al., "Alterations of Fas (Apo-1/CD95) gene in non-small cell lung cancer," Oncogene, vol. 18, no. 25, pp. 3754-3760, 1999.

[299] S. H. Lee, M. S. Shin, W. S. Park, et al., "Alterations of Fas (APO-1/CD95) gene in transitional cell carcinomas of urinary bladder," Cancer Research, vol. 59, no. 13, pp. 30683072, 1999.

[300] W. S. Park, R. R. Oh, Y. S. Kim, et al., "Somatic mutations in the death domain of the Fas (Apo-I/CD95) gene in gastric cancer," Journal of Pathology, vol. 193, no. 2, pp. 162-168, 2001.

[301] I. I. Wistuba, C. Behrens, A. K. Virmani, et al., "Allelic losses at chromosome 8p21-23 are early and frequent events in the pathogenesis of lung cancer," Cancer Research, vol. 59, no. 8, pp. 1973-1979, 1999.

[302] M. Emi, Y. Fujiwara, T. Nakajima, et al., "Frequent loss of heterozygosity for loci on chromosome $8 \mathrm{p}$ in hepatocellular carcinoma, colorectal cancer, and lung cancer," Cancer Research, vol. 52, no. 19, pp. 5368-5372, 1992.
[303] O. Micheau, "Cellular FLICE-inhibitory protein: an attractive therapeutic target?" Expert Opinion on Therapeutic Targets, vol. 7, no. 4, pp. 559-573, 2003.

[304] A. M. Hunter, E. C. LaCasse, and R. G. Korneluk, "The inhibitors of apoptosis (IAPs) as cancer targets," Apoptosis, vol. 12, no. 9, pp. 1543-1568, 2007.

[305] S. Fulda, "Caspase-8 in cancer biology and therapy," Cancer Letters, vol. 281, no. 2, pp. 128-133, 2009.

[306] S. Kitada, I. M. Pedersen, A. D. Schimmer, and J. C. Reed, "Dysregulation of apoptosis genes in hematopoietic malignancies," Oncogene, vol. 21, no. 21, pp. 3459-3474, 2002.

[307] N. Rampino, H. Yamamoto, Y. Ionov, et al., "Somatic frameshift mutations in the BAX gene in colon cancers of the microsatellite mutator phenotype," Science, vol. 275, no. 5302, pp. 967-969, 1997.

[308] S. S. Zinkel, C. C. Ong, D. O. Ferguson, et al., "Proapoptotic BID is required for myeloid homeostasis and tumor suppression," Genes and Development, vol. 17, no. 2, pp. 229-239, 2003.

[309] H. Tagawa, S. Karnan, R. Suzuki, et al., "Genome-wide array-based CGH for mantle cell lymphoma: identification of homozygous deletions of the proapoptotic gene BIM," Oncogene, vol. 24, no. 8, pp. 1348-1358, 2005.

[310] C. Mestre-Escorihuela, F. Rubio-Moscardo, J. A. Richter, et al., "Homozygous deletions localize novel tumor suppressor genes in B-cell lymphomas," Blood, vol. 109, no. 1, pp. 271280, 2007.

[311] D. R. Fels and C. Koumenis, "The PERK/eIF2 $\alpha /$ ATF4 module of the UPR in hypoxia resistance and tumor growth," Cancer Biology \& Therapy, vol. 5, no. 7, pp. 723-728, 2006.

[312] C. Koumenis and B. G. Wouters, “"Translating” tumor hypoxia: unfolded protein response (UPR)-dependent and UPR-independent pathways," Molecular Cancer Research, vol. 4, no. 7, pp. 423-436, 2006.

[313] H.-C. Zheng, H. Takahashi, X.-H. Li, et al., "Overexpression of GRP78 and GRP94 are markers for aggressive behavior and poor prognosis in gastric carcinomas," Human Pathology, vol. 39, no. 7, pp. 1042-1049, 2008.

[314] P. Pyrko, A. H. Schonthal, F. M. Hofman, T. C. Chen, and A. S. Lee, "The unfolded protein response regulator GRP78/BiP as a novel target for increasing chemosensitivity in malignant gliomas," Cancer Research, vol. 67, no. 20, pp. 9809-9816, 2007.

[315] A. C. Koong, V. Chauhan, and L. Romero-Ramirez, "Targeting XBP-1 as a novel anti-cancer strategy," Cancer Biology \& Therapy, vol. 5, no. 7, pp. 756-759, 2006.

[316] S. Qin and P. B. Chock, "Implication of phosphatidylinositol 3-kinase membrane recruitment in hydrogen peroxideinduced activation of PI3K and Akt," Biochemistry, vol. 42, no. 10, pp. 2995-3003, 2003.

[317] S. Pervaiz, J. Cao, O. S. P. Chao, Y. Y. Chin, and M.-V. Clement, "Activation of the RacGTPase inhibits apoptosis in human tumor cells," Oncogene, vol. 20, no. 43, pp. 62636268, 2001.

[318] D. Mahalingam, R. Swords, J. S. Carew, S. T. Nawrocki, K. Bhalla, and F. J. Giles, "Targeting HSP90 for cancer therapy," British Journal of Cancer, vol. 100, no. 10, pp. 1523-1529, 2009.

[319] C. Garrido, M. Brunet, C. Didelot, Y. Zermati, E. Schmitt, and G. Kroemer, "Heat shock proteins 27 and 70: antiapoptotic proteins with tumorigenic properties," Cell Cycle, vol. 5, no. 22, pp. 2592-2601, 2006. 

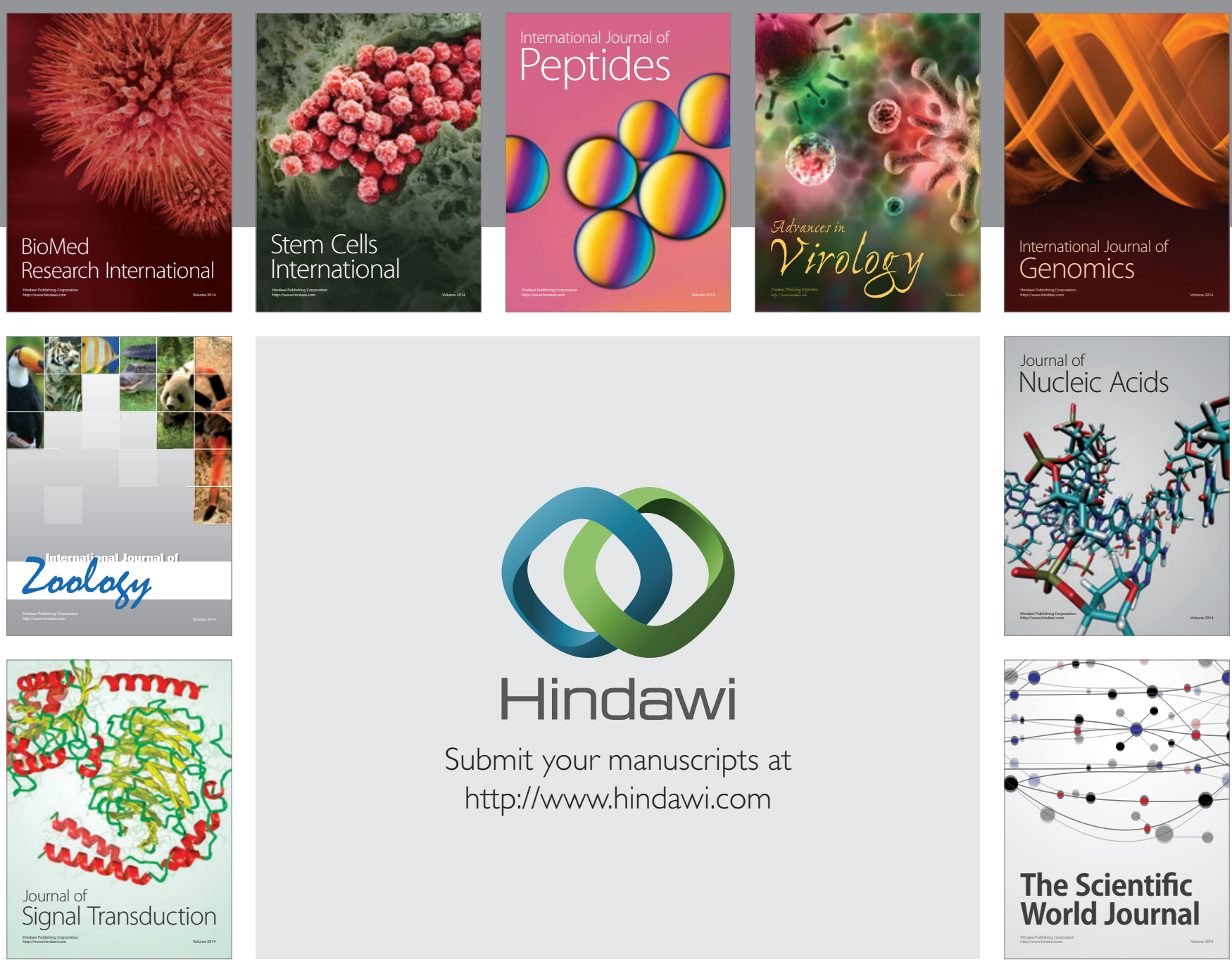

Submit your manuscripts at

http://www.hindawi.com
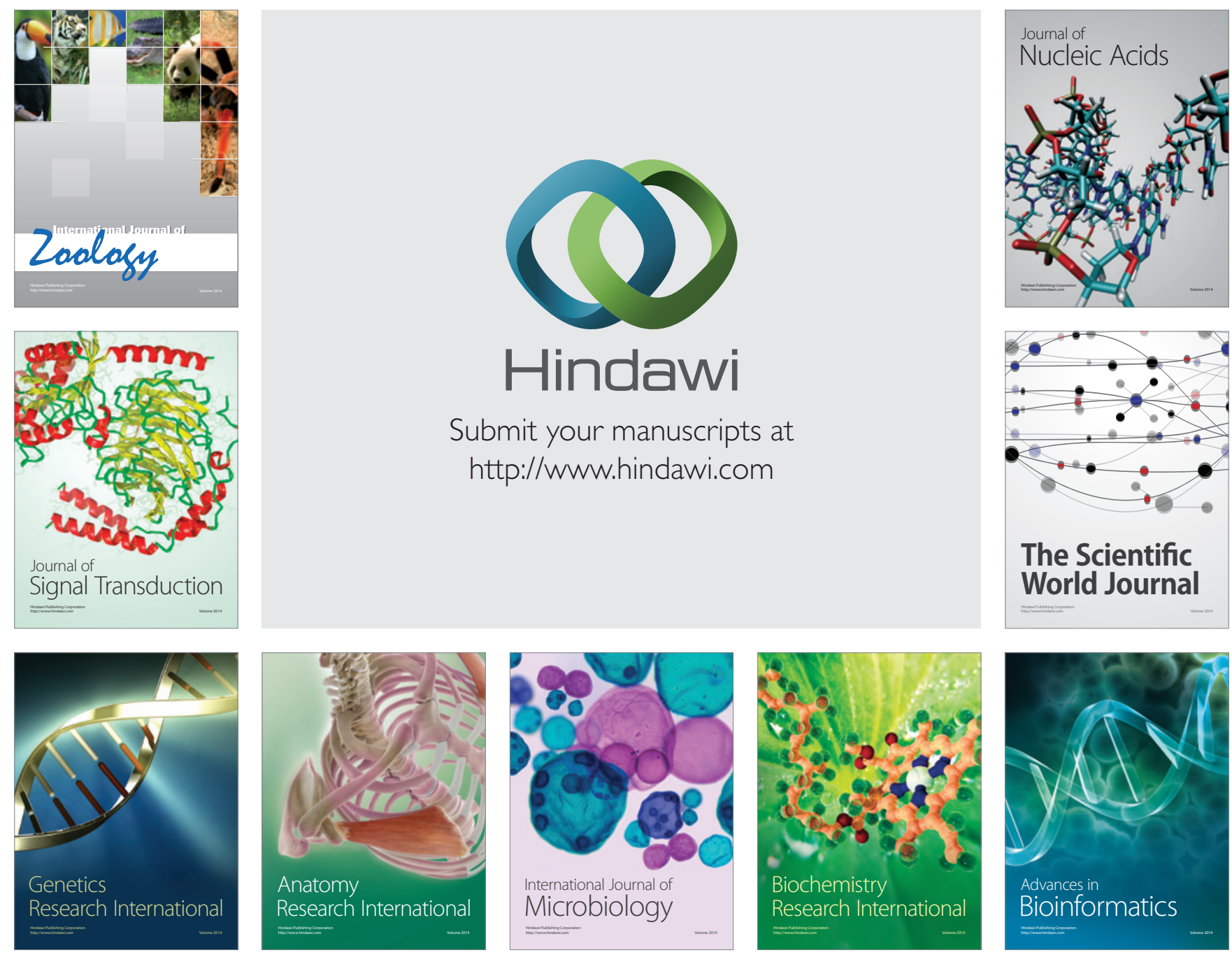

The Scientific World Journal
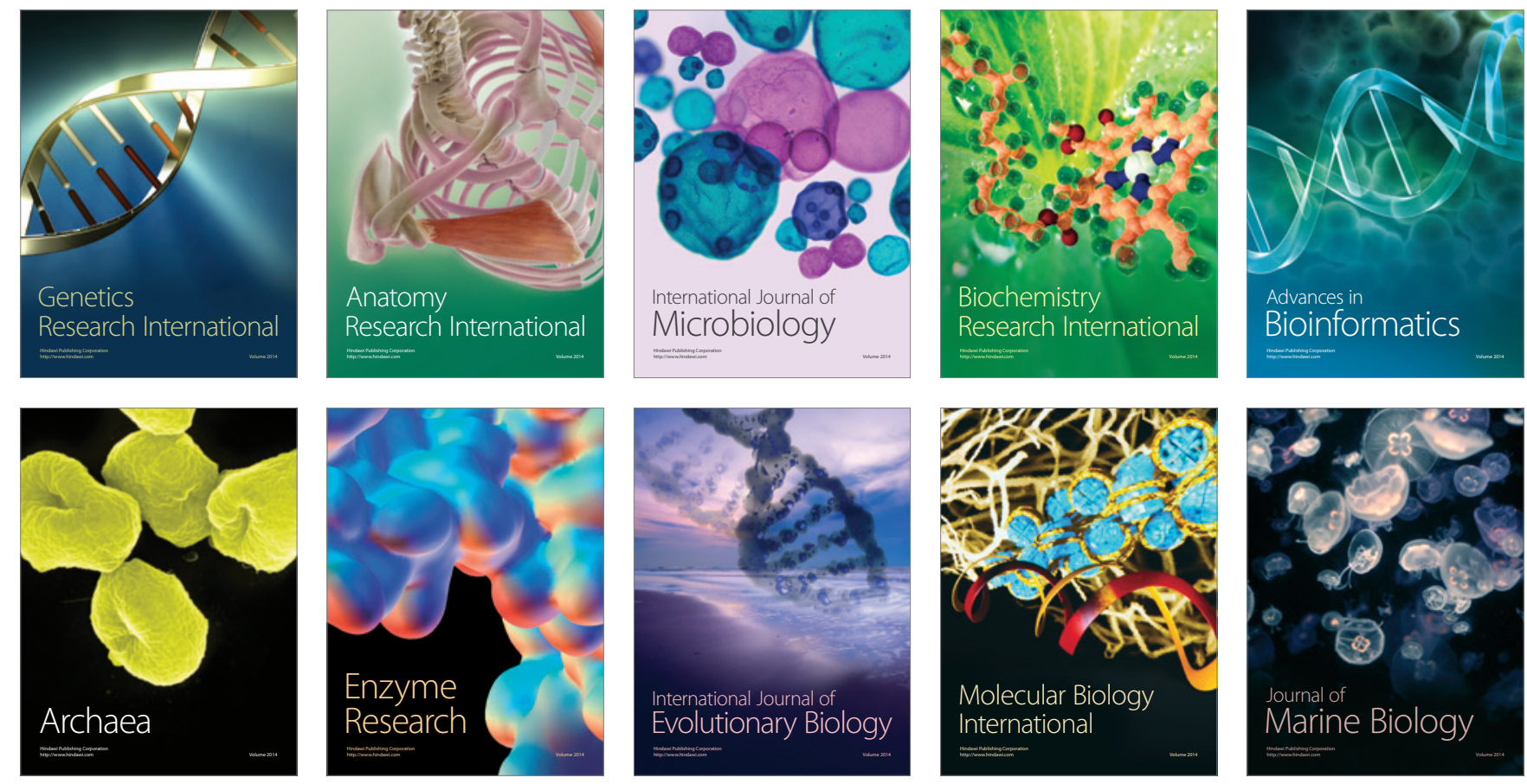